\title{
Distinct and Non-Redundant Roles of Microglia and Myeloid Subsets in Mouse Models of Alzheimer's Disease
}

\author{
Alexander Mildner, ${ }^{1 \star}$ Bernhard Schlevogt, ${ }^{2 \star}$ Katrin Kierdorf, ${ }^{1,6 *}$ Chotima Böttcher, ${ }^{3}$ Daniel Erny, ${ }^{1}$ Markus P. Kummer, ${ }^{4}$ \\ Michael Quinn, ${ }^{3}$ Wolfgang Brück, ${ }^{2}$ Ingo Bechmann, ${ }^{5}$ Michael T. Heneka, ${ }^{4}$ Josef Priller, ${ }^{3 \star}$ and Marco Prinz ${ }^{1 \star}$ \\ ${ }^{1}$ Department of Neuropathology, University of Freiburg, D-79106 Freiburg, Germany, ${ }^{2}$ Department of Neuropathology, Universitätsmedizin Göttingen, \\ D-37099 Göttingen, Germany, ${ }^{3}$ Department of Neuropsychiatry and Laboratory of Molecular Psychiatry, BCRT and NeuroCure, Charité- \\ Universitätsmedizin Berlin, D-10117 Berlin, Germany, ${ }^{4}$ Department of Neurology, Rheinische Friedrich-Wilhelms-Universität, D-53127 Bonn, Germany, \\ ${ }^{5}$ Institute of Anatomy, University of Leipzig, D-04103 Leipzig, Germany, and ${ }^{6}$ Faculty of Biology, University of Freiburg, D-79104 Freiburg, Germany
}

Mononuclear phagocytes are important modulators of Alzheimer's disease (AD), but the specific functions of resident microglia, bone marrow-derived mononuclear cells, and perivascular macrophages have not been resolved. To elucidate the spatiotemporal roles of mononuclear phagocytes during disease, we targeted myeloid cell subsets from different compartments and examined disease pathogenesis in three different mouse models of $\mathrm{AD}\left(A P P^{\text {swe/PS1 }}, A P P^{\text {swe }}\right.$, and APP23 mice). We identified chemokine receptor 2 (CCR2)expressing myeloid cells as the population that was preferentially recruited to $\beta$-amyloid (A $\beta$ ) deposits. Unexpectedly, AD brains with dysfunctional microglia and devoid of parenchymal bone marrow-derived phagocytes did not show overt changes in plaque pathology and $\mathrm{A} \beta$ load. In contrast, restriction of CCR 2 deficiency to perivascular myeloid cells drastically impaired $\beta$-amyloid clearance and amplified vascular $\mathrm{A} \beta$ deposition, while parenchymal plaque deposition remained unaffected. Together, our data advocate selective functions of CCR2-expressing myeloid subsets, which could be targeted specifically to modify disease burden in AD.

\section{Introduction}

A local activation of microglial cells is consistently detected in the brains of patients with Alzheimer's disease (AD), but the role of activated peripheral myeloid cells in the pathogenesis of AD has not been resolved (Akiyama et al., 2000; Prinz and Mildner, 2011). For example, microglial cells have been suggested to be responsible for pathological $\beta$-amyloid $(\mathrm{A} \beta)$ protein deposition (Wisniewski et al., 1989; Akiyama et al., 2000; Frackowiak et al., 2005), but at the same time, they have also been implicated in $\mathrm{A} \beta$ clearance (Chung et al., 1999; Bard et al., 2000; Wyss-Coray et al., 2001; Jantzen et al., 2002). Moreover, it has been shown recently that the interaction of CD40 with CD40 ligand on the surface of microglia is an important molecular signal for microglia activation in AD mouse models (Tan et al., 1999, 2002; Gate et al., 2010).

\footnotetext{
Received Nov. 29, 2010; revised May 26, 2011; accepted May 31, 2011.

Author contributions: A.M., W.B., M.T.H., J.P., and M.P. designed research; B.S., K.K., C.B., D.E., M.P.K., M.Q., I.B., and M.P. performed research; M.T.H. contributed unpublished reagents/analytic tools; A.M., B.S., K.K., C.B., D.E., M.P.K., M.Q., I.B., W.B., and M.P. analyzed data; J.P. and M.P. wrote the paper.

${ }^{*}$ A.M., B.S., K.K., J.P., and M.P. contributed equally to this work.

This work was supported by the German Research Council (DFG, PR 577/5-1 and FOR1336 to M.P.. I.B., and J.P.). M.P. was supported by the Bundesministerium fuer Bildung und Forschung-funded competence network of neurodegenerative disorders (DZNE). A.M. was a fellow of the Gertrud Reemtsma Foundation. We thank Olga Kowatsch, Doris Bode, and Tina El Gaz for excellent technical assistance; Dr. Matthias Staufenbiel for providing APP23 mice; and Drs. Bettina Bert and Heidrun Fink for behavioral analysis.

The authors declare no conflict of interest.

A. Mildner's present address: Department of Immunology, The Weizmann Institute of Science, Rehovot 76100, Israel.

Correspondence should be addressed to Dr. Marco Prinz, Department of Neuropathology, University of Freiburg, Breisacher Strasse 64, D-79106 Freiburg, Germany. E-mail: marco.prinz@uniklinik-freiburg.de.

DOI:10.1523/JNEUROSCI.6209-10.2011

Copyright $\odot 2011$ the authors $\quad 0270-6474 / 11 / 3111159-13 \$ 15.00 / 0$
}

Recent work using GFP-labeled bone marrow (BM) chimeras and total-body irradiation increased the longstanding controversy over the issue of whether endogenous microglia or BM-derived phagocytes are beneficial or detrimental in neurodegeneration. One study concluded that BM-derived phagocytes are critical for restricting $\mathrm{A} \beta$ plaque formation (Simard et al., 2006). Other groups found that mononuclear phagocytes represent the minority of blood-borne cells, which engraft in the brains of APP23 transgenic mice (Stalder et al., 2005). A possible involvement of microglia in the pathogenesis of $\mathrm{AD}$ was suggested by a recent study showing that chemokine receptor 2 (CCR2) deficiency diminished the migratory potential of microglia and reduced the clearance of $A \beta$ in transgenic $A P P^{\text {swe }}$ mice (El Khoury et al., 2007). Moreover, stimulation of perivascular macrophage turnover reduced cerebral amyloid angiopathy (CAA) load independent of clearance by microglia (Hawkes and McLaurin, 2009). Blockade of innate immune responses by interruption of TGF- $\beta$-Smad $2 / 3$ signaling in myeloid cells mitigated AD pathology and attenuated parenchymal and cerebrovascular A $\beta$ deposits (Town et al., 2008).

One major caveat of all reports using BM chimeras, however, is the usage of total-body irradiation (including the brain) before BM transplantation to discriminate donor hematopoietic cells from resident microglia in the hosts (Malm et al., 2005; Stalder et al., 2005; Simard et al., 2006; Grathwohl et al., 2009), which potentially changes the brain microenvironment (Ajami et al., 2007; Mildner et al., 2007).

Furthermore, the direct circulating phagocyte or its progenitor immigrating into the diseased $\mathrm{AD}$ brain has not been identified yet. Ly-6C hi monocytes have been shown to be recruited into 
the inflamed CNS during autoimmune demyelination (Mildner et al., 2009), and bacterial (Mildner et al., 2008) and viral infection (Getts et al., 2008) with different roles for disease pathogenesis. Whether these monocyte subsets are involved in neurodegeneration of the CNS is not yet known. We therefore used a combinational approach of bone marrow transplantation and partial-body irradiation (head shielded, protected CNS) versus whole-body irradiation (unprotected CNS) to examine the engraftment of myeloid subsets and to circumvent the caveats of brain irradiation in mouse models of AD.

\section{Materials and Methods}

Mice and generation of BM chimeric mice. Bone marrow chimeric mice were generated as described recently (Mildner et al., 2007). In brief, recipient mice were reconstituted with bone marrow cells (BMCs) derived from tibias and femurs from adult $\beta$-actin (ACT $\beta)$-EGFP mice alone $\left(C C R 2^{+/+} G F P^{+}\right)$or from double-mutant animals intercrossed with CCR2 ko mice $\left(C C R 2^{-/-} G F P^{+}\right)$. Specific body (protected) irradiation of mice was performed by a $6 \mathrm{MV}$ X-ray Varian linear accelerator. Mice were put into a $20 \times 20 \times 3 \mathrm{~cm}$ cast Perspex-lined chamber $(5 \mathrm{~mm}$ gauge, density $1.18 \mathrm{~g} / \mathrm{cm}^{3}$ ) subdivided into eight single compartments and equipped with a removable cap. Spiracles were provided, and the heads of the mice were carefully adjusted to them. Mice were treated with parallel opposed fields with a maximum dose at a depth of $1.5 \mathrm{~cm}$. The field size was adjusted to $14 \times 20 \mathrm{~cm}$, and therefore, the brains of the animals were outside the irradiation fields, and only the body was irradiated. A safety margin of $0.5 \mathrm{~cm}$ from the field border to the head was preserved, so that no dose could affect normal brain tissue. Dosimetry data were measured in a water phantom and corrected for the presence of tissue inhomogeneities and surrounding air. A total of $5 \times 10^{6} \mathrm{CCR}^{-1-} \mathrm{GFP}^{+}$or $C C R 2^{+/+} \mathrm{GFP}^{+}$BMCs were injected into the tail vein of recipients $24 \mathrm{~h}$ after irradiation. Since the skull bone marrow contributes to hematopoiesis, the reconstitution levels of chimeric mice were $\sim 60 \%$, resulting in a total of $30-40 \% \mathrm{GFP}^{+}$cells. We therefore adapted the reconstitution level of total-irradiated (unprotected) mice by mixing $C C R 2^{-1-} G F P^{+}$or $C C R 2^{+/+} \mathrm{GFP}^{+}$BMCs in a 1:3 ratio with CCR2 $2^{+/+}$BMCs, which resulted in similar reconstitution levels in all chimeric mice. Only protected and unprotected mice with a similar grade of myeloid chimerism were chosen for subsequent comparative analysis. All mice received an irradiation dosage of $1100 \mathrm{cGy}$ and were injected with $5 \times 10^{6}$ BMCs into the tail vein, $24 \mathrm{~h}$ after the irradiation. $A P P^{\text {swe/PS1 }}$ mice $[\mathrm{Tg}(A P P 695) 3 D b o T g(P S E N 1) 5 D b o / J]$ were obtained from The Jackson Laboratory. APP23 mice were a kind gift from Matthias Staufenbiel, Novartis Institutes for BioMedical Research. Tg2576 $A P P^{\text {swe }}$ mice were from Taconic. Mice were bred in-house under pathogen-free conditions. Females were used in all experiments.

Six to eight weeks after grafting, reconstitution was assessed by FACS analysis of peripheral blood. Blood samples were prepared at $4^{\circ} \mathrm{C}$ in buffer solution (PBS containing 2\% FCS and 5 mM EDTA) and stained with CD11b, Ly-6C (eBioscience, BD PharMingen) as described previously (Mildner et al., 2009). For comparison of macrophages, adult microglia and Ly-6C ${ }^{\text {hi }}$ monocytes of $C C R 2^{+/+}, C C R 2^{-/-}, C C R 2^{-/-}$ $\mathrm{GFP}^{+}$, and CCR2 ${ }^{+/+} \mathrm{GFP}^{+}$animals, cells were stained for $\alpha 4$-integrin, $\beta 1$-integrin, PSGL-1 (P-selectin glycoprotein ligand-1), and CD11c (eBioscience, BD PharMingen). After lysis of erythrocytes with FACS lysis solution (Becton Dickinson) and washing, cell suspensions were analyzed on a FACS Calibur (Becton Dickinson). Data were acquired with WinMDI and FlowJo.

Quantification of phagocyte engraftment in the CNS. After transcardial perfusion with PBS and subsequent $4 \%$ paraformaldehyde, $20 \mu \mathrm{m}$ cryosections were obtained from the brains. Sections were incubated in PBS containing 5\% fetal calf serum. Primary and preabsorbed antibodies were added overnight at a dilution of 1:100 for Iba-1 (Wako). Amyloid was stained with anti-human amyloid- $\beta$ antibody (Signet antibodies; Covance), the antibody was added overnight at a dilution of 1:100. Cy3conjugated secondary antibodies (Dianova) were added at a dilution of 1:100 for Iba- 1 and 1:600 for other antibodies for $1 \mathrm{~h}$. Nuclei were counterstained with 4,6-diamidino-2-phenylindole (DAPI). GFP-expressing ramified cells and $\mathrm{Iba}-1^{+}$microglia were counted in at least three sections each of individual animal. Quantification was performed independently by two scientists in a blinded manner. The results were compared with stereological analysis using a Leica DMRB/DIC fluorescence research microscope (100× magnification) and quantified using the optical fractionator method (Stereo Investigator system, MicroBrightField Bioscience). The number of engrafted cells was examined microscopically at a $200 \times$ microscopic magnification using a conventional fluorescence microscope (Olympus BX-61) equipped with a color camera (Olympus DP71).

Laser microdissection. Microdissection of microglia was performed using a Zeiss PALM MicroBeam as described previously, with modification (Raasch et al., 2011). Fast immunochemistry of serial sections was performed with CD11b antibodies (Serotec). Immunostained sections were counterstained with DAPI to facilitate the identification of individual cells. RNA was isolated with the RNeasy Micro Plus Kit (Qiagen), and reverse transcription (RT), preamplification, and real-time PCR were performed using Applied Biosystems reagents according to the manufacturer's recommendations.

Real-time PCR. RNA was extracted from brains at indicated time points after or without irradiation. The tissue was flushed with ice-cold HBSS and RNA was isolated using RNAeasy Mini kits (Qiagen) following the manufacturer's instructions. The samples were treated with DNase I (Roche), and $1 \mu \mathrm{g}$ of RNA was transcribed into cDNA using oligo-dT primers and the SuperScript II RT kit (Invitrogen). cDNA $(2.5 \mu \mathrm{l})$ was transferred into a 96-well Multiply PCR plate (Sarstedt), and $12.5 \mu \mathrm{l}$ of ABsolute QPCR SYBR Green Master Mix (ABgene) plus $9.6 \mu$ l of dd $\mathrm{H}_{2} \mathrm{O}$ were added. The PCR was performed as described recently (Prinz et al., 2006). The following primer probe pairs were used: CCL3 (sense, TGCCCACGTCAAGGAGTATTT; antisense, TCTCTGGGTTGGCACACACTT), CXCL10 (sense, TGCTGGGTCTGAGTGGGACT; antisense, CCCTATGGCCCTCATTCTCAC), TNF $\alpha$ (sense, CATCTTCTCAAAATTCGAGTGACAA; antisense, TGGGAGTAGACAAGGTACAACCC), CCL2 (sense, TCTGGGCCTGCTGTTCACC; antisense, TTGGGATCATCTTGCTGGTG).

$A \beta$ quantifications. Quantification of $\mathrm{A} \beta$ was performed using human amyloid $\beta 1-40$ and $\beta 1-42$ ELISA kits (The Genetics Company) according to the manufacturer's protocol. Forebrains of mice were homogenized in PBS containing $1 \mathrm{~mm}$ EDTA and EGTA and protease inhibitor mixture, further extracted in RIPA buffer (containing, in mM: 25 Tris$\mathrm{HCl}, \mathrm{pH} 7.5,150 \mathrm{NaCl}, 1 \%$ Nonidet P-40, 0.5\% sodium deoxycholate, $0.1 \%$ SDS), and centrifuged at $20,000 \times g$ for $30 \mathrm{~min}$, and the pellet was solubilized in $2 \%$ SDS, 25 mm Tris- $\mathrm{HCl}$, pH 7.5. Samples were separated by NuPAGE and immunoblotted using antibodies against APP, $\beta$-Cterminal fragment $(\beta-\mathrm{CTF})$, and $\mathrm{A} \beta$, and antibody E7 (Developmental Studies Hybridoma Bank), followed by incubation with appropriate secondary antibodies. Immunoreactivity was detected by enhanced chemiluminescence reaction (Millipore).

Statistical analysis. Statistical differences of clinical scores were evaluated using a nonpaired Student's $t$ test. Differences were considered significant when $p<0.05$.

\section{Results}

\section{Engraftment of BM-derived phagocytes in the brains of $\mathrm{AD}$ transgenic mice depends on CCR2}

We generated double transgenic mice by intercrossing $A C T \beta$ EGFP mice with $C C R 2^{-/-}$animals and obtained individuals that express GFP on CCR2 $2^{+/+}\left(C C R 2^{+/+}\right.$GFP $)$or $C C R 2^{-/-}\left(C C R 2^{-/-}\right.$ GFP) background, respectively. To distinguish invading BMderived mononuclear cells from brain endogenous microglia in transgenic mouse models of $\mathrm{AD}$, we generated $\mathrm{BM}$ chimeras. Respective GFP-marked BM cells were transplanted into lethally total-body irradiated (including the brain) recipient $A P P^{\text {swe/PS1 }}$ transgenic mice. $C C R 2^{-/-}$mice have a strong and specific reduction of the Ly-6C ${ }^{\text {hi }}$ subpopulation of monocytes (Serbina and Pamer, 2006; Mildner et al., 2007). As expected, peripheral blood Ly-6 $\mathrm{C}^{\text {hi }}$ monocytes were strongly dimin- 
A
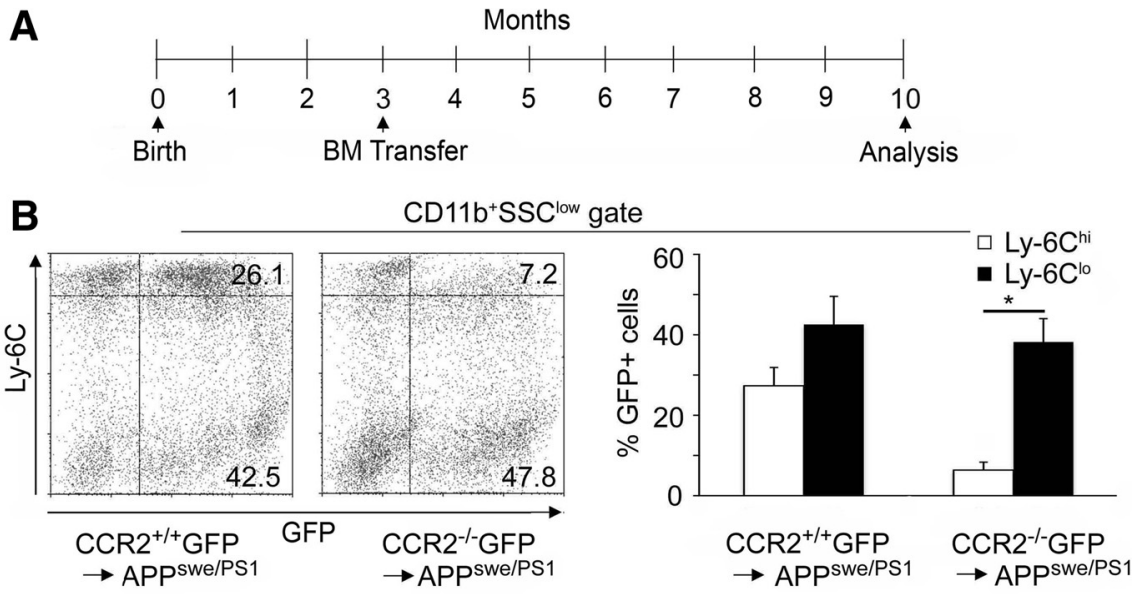

C

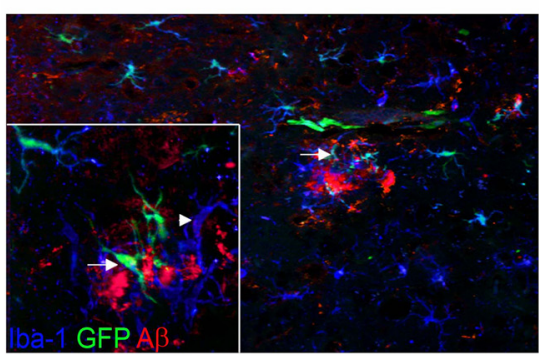

$\mathrm{CCR}^{+/+} \mathrm{GFP} \rightarrow$ APPswe/PS1
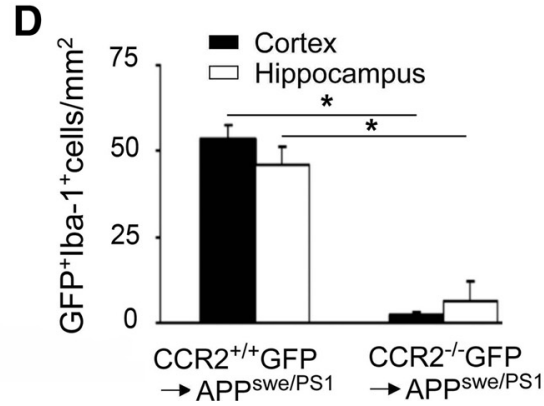

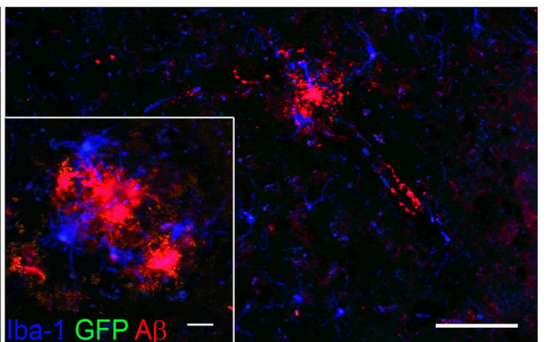

$\mathrm{CCR}^{-1-\mathrm{GFP}} \rightarrow \mathrm{APP}^{\mathrm{sw} e / P S} 1$

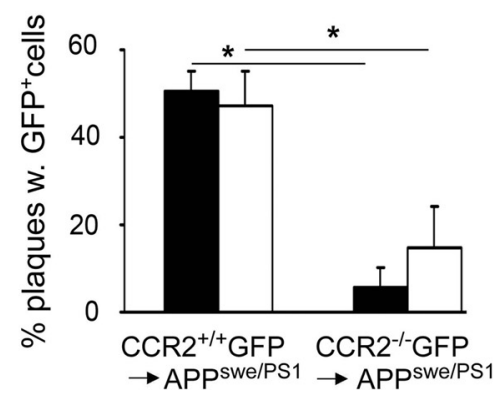

Figure 1. Engraftment of BM-derived phagocytes in the brains of AD transgenic mice depends on CCR2. A, Time scale of BM transfer experiments performed in $A P P^{\text {Swe/PS1 }}$ animals. Arrows mark the time points of generation and subsequent analysis of $C C R 2^{+/+}$GFP $\rightarrow$ APP ${ }^{\text {swe/PS1 }}$ and $C C R 2^{-/-}$GFP $\rightarrow A P P^{\text {swe/PS1 }}$ chimeric mice. B, FACS analysis of peripheral blood 10 months after $B M$ cell transfer reveals a lack of GFP ${ }^{+}$Ly-6C ${ }^{\text {hi }}$ monocytes in CCR2 $2^{-/-}$GFP $\rightarrow$ APPswe/PS1 chimeras compared with CCR2 $^{+/+}$ GFP donors. Percentages of the respective cell populations are indicated. Representative dot blots for the chimeric groups (left) and quantification of GFP ${ }^{+} \mathrm{CD}_{11 \mathrm{~b}}{ }^{+} \mathrm{Ly}-6 \mathrm{C}^{\text {hi }}$ and GFP ${ }^{+} \mathrm{CD} 11 \mathrm{~b}{ }^{+} \mathrm{Ly}-6 \mathrm{C}^{\mathrm{lo}}$ cells (right) are shown. Data are expressed as means \pm SEM. SSC, Side scatter. At least 5 mice per group were assessed. ${ }^{*} p<0.05$ statistical significance. $C$, Immunohistochemistry of ${ }_{A P P}{ }^{5 w e / P S 1}$ BM chimeric brains. Fluorescence microscopy reveals a significant number of GFP-positive ramified cells in the hippocampus of $C\left(R 2^{+/+}\right.$GFP $\rightarrow A P P^{\text {swe/PS1 }}$ mice (left), but very few in $C\left(R 2^{-/-}\right.$GFP $\rightarrow A P P^{\text {swe/PS1 }}$ mice (right). Iba- 1 immunoreactivity (blue) for phagocytes shows that some branched cells are GFP ${ }^{+}$and therefore of donor origin (GFP, green, arrows), whereas others represent endogenous microglia expressing only lba-1 (arrowheads). Immunostaining of $\beta$-amyloid is shown in red. Scale bars: $100 \mu \mathrm{m}$ (overviews) and $25 \mu \mathrm{m}$ (insets). D, Semiquantitative analysis of phagocyte engraftment (GFP ${ }^{+}$Iba- $^{+}{ }^{+}$ cells) per area (left) and per $\beta$-amyloid plaque (right) in the hippocampus and cortex of BM chimeric animals. Bars show the means \pm SEM from at least three sections per individual animal ( $n \geq 5$ per group). ${ }^{*} p<0.05$ statistical significance.

ished in $C C R 2^{-1-}$ GFP $\rightarrow A P P^{\text {swe/PS1 }}$ chimeric mice compared with $C C R 2^{+/+} G F P \rightarrow A P P^{\text {swe/PS1 }}$ mice 7 months after BM transplantation (Fig. $1 A, B$ ). Notably, the general reconstitution efficacy was similar in both chimeric groups, as indicated by comparable numbers of $\mathrm{Ly}-6 \mathrm{C}^{\text {lo }} \mathrm{GFP}^{+}$cells in the circulation.

To assess the ability of GFP-marked myeloid subsets derived from transplanted $\mathrm{BM}$ to differentiate into tissue macrophages in the AD brain, we histologically analyzed recipient mice 7 months after BM transplantation (Fig. 1C). Microscopic investigation of the hippocampus and the cortex revealed numerous parenchymal cells with ramified morphology. These donor-derived cells were positive for the microglia/macrophage marker, Iba-1, and partially decorated $\mathrm{A} \beta$ plaques. Notably, $\mathrm{GFP}^{+} \mathrm{Iba}-1^{+}$cells were predominantly found in the CNS of $C C R 2^{+/+} G F P \rightarrow$ $A P P^{\text {swe/PS1 }}$ mice, whereas the number of engrafted myeloid cells in $C C R 2^{-/-}$GFP $\rightarrow$ $A P P^{\text {swe/PSI }}$ chimeras was greatly reduced in the hippocampus $\left(6.2 \pm 5.8 \mathrm{cells} / \mathrm{mm}^{2}\right.$ in $C C R 2^{-/-}$GFP $\rightarrow A P P^{\text {swe/PS1 }}$ compared with $45.8 \pm 4.6$ cells $/ \mathrm{mm}^{2}$ in $\mathrm{CCR} 2^{+/+} \mathrm{GFP} \rightarrow$ $\left.A P P^{\text {swe/PS1 }}\right)$ and in the cortex $(2.3 \pm 0.8$ cells $/ \mathrm{mm}^{2}$ in $C C R 2^{-/-}$GFP $\rightarrow A P P^{\text {swe/PS1 }}$ compared with $53.2 \pm 4.0$ cells $/ \mathrm{mm}^{2}$ in $C C R 2^{+/+}$GFP $\rightarrow$ APP ${ }^{\text {swe/PS1 }}$, Fig. 1D). Interestingly, only $\sim 50 \%$ of hippocampal and cortical $\mathrm{A} \beta$ plaques were surrounded by engrafted $\mathrm{GFP}^{+} \mathrm{Iba}^{+}{ }^{+}$cells. As expected, significantly fewer $\mathrm{A} \beta$ deposits were decorated by immigrated $\mathrm{GFP}^{+}$cells in $C C R 2^{-/-}$ $G F P \rightarrow A P P^{\text {swe/PS1 }}$ mice (Fig. $1 D$, right).

In conclusion, our data suggest that CCR2-expressing BM-derived cells are the main source of donor-derived $\mathrm{Iba}-1^{+}$ phagocytes in several brain regions with AD pathology after total-body irradiation and BM transplantation.

\section{Irradiation conditions the brain for mononuclear phagocyte engraftment in AD transgenic mice}

The possibility that total-body irradiation conditions the brain for phagocyte engraftment from the circulation has not been addressed in earlier studies on neurodegeneration in $\mathrm{AD}$. We therefore adapted previous protocols using linear acceleration, which allow for selective irradiation that includes or excludes the brain before BM transplantation. These BM chimeras are subsequently referred to as "protected" mice, in contrast to the "unprotected" ones. As expected, the number of circulating donor-derived $\mathrm{CD}_{1} 1 \mathrm{~b}^{+}$ Ly-6C ${ }^{\text {hi }} \mathrm{GFP}^{+}$and $\mathrm{CD} 11 \mathrm{~b}^{+} \mathrm{Ly}-6 \mathrm{C}^{\text {lo }} \mathrm{GFP}^{+}$ monocytes was slightly decreased in protected $C C R 2^{+/+} \mathrm{GFP} \rightarrow A P P^{\text {swe/PS1 }}$ mice (APP $P^{\text {swe/PS1 }}$ protected) compared with the unprotected situation ( $A P P^{\text {swe/PS1 }}$ unprotected), because skull hematopoiesis was excluded from irradiation (Fig. $2 \mathrm{~A}$ ).

Importantly, histopathological analysis of the brains of $A P P^{\text {swe/PSI }}$ mice 7 months after BM transplantation revealed phagocyte engraftment only in regions of the brain that were conditioned by irradiation (Fig. 2 B). In fact, amyloid plaques in irradiated cortex and hippocampus were partially surrounded by donor-derived $\mathrm{GFP}^{+} \mathrm{Iba}-1^{+}$cells, whose cell bodies were distal from the edges of the deposits and whose cellular processes were directed toward the center of the plaques without apparently reaching the core of the deposits. Subsequent quantitative measurements revealed a comparable number of GFP-positive cells in hippocampal and cortical brain regions of 
A CD11b+SSClow gate
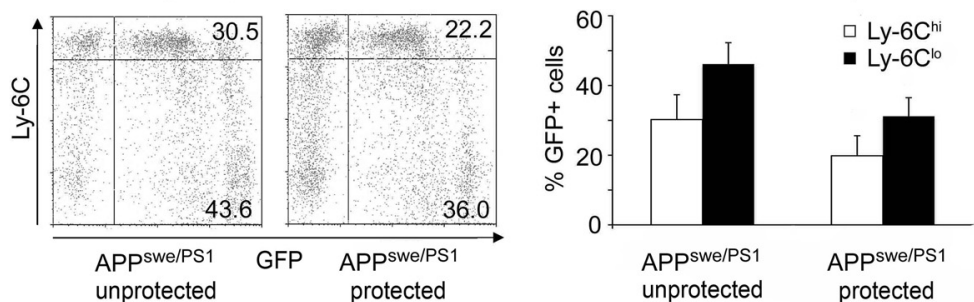

B

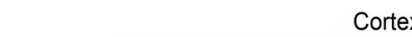

Cortex

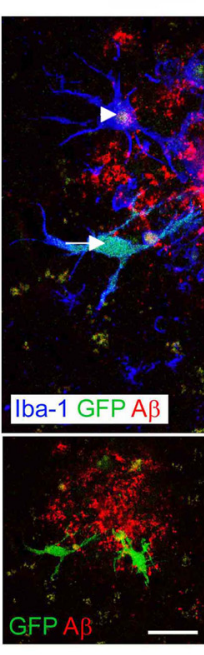

C

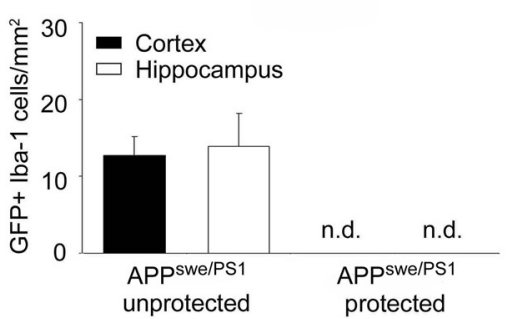

APPswe/PS1 protected

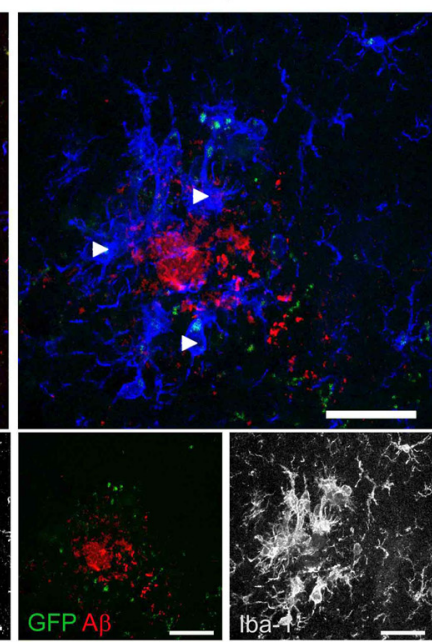

D

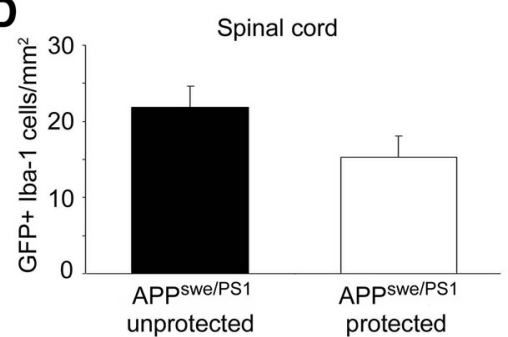

Hippocampus

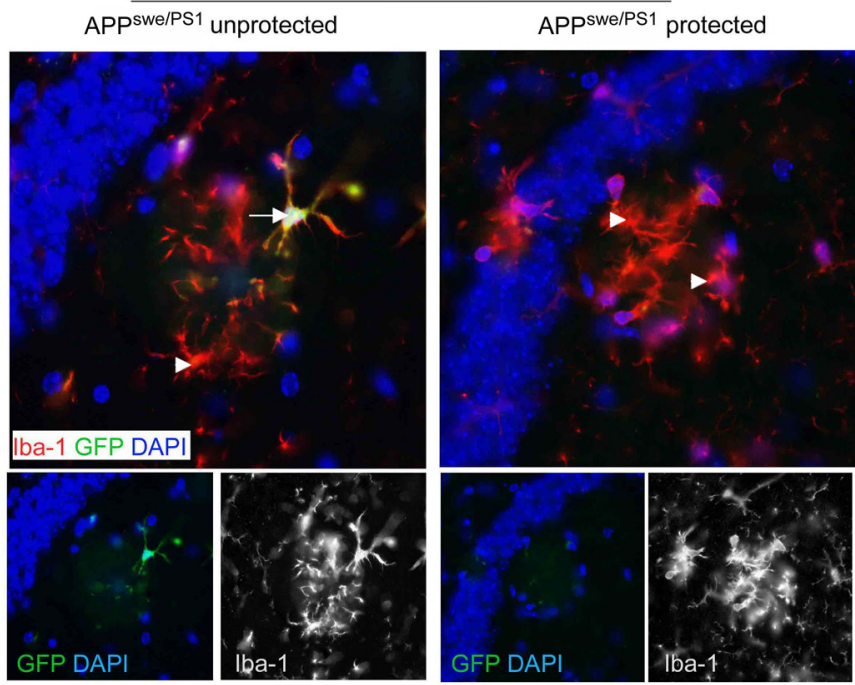

E

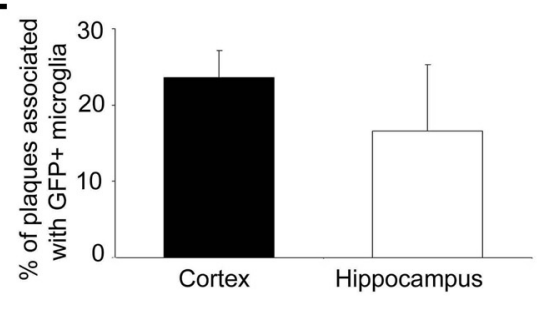

Figure 2. CNS conditioning enhances the recruitment of BM-derived mononuclear phagocytes into the brains of AD transgenic mice. A, Assessment of blood chimerism in brain-protected and unprotected $C C R 2^{+/+}$GFP $\rightarrow A P P^{\text {swe/PS1 }}$ chimeras. Representative dot plots from individual mice are shown on the left, and the percentages of GFP ${ }^{+} \mathrm{CD}_{11 b^{+}} \mathrm{Ly}_{-} 6 \mathrm{CC}^{\mathrm{lo}}$ and GFP ${ }^{+} \mathrm{CD} 11 \mathrm{~b}^{+} \mathrm{Ly}^{-6 \mathrm{C}^{\text {hi }}}$ cells are indicated. SSC, Side scatter. Quantification of Ly- $6 C^{10}$ - and Ly- $6 C^{\text {hi }}$-expressing GFP-positive cells in the peripheral blood of unprotected and protected $C C R 2^{+/+}{ }^{+} F P \rightarrow A P P$ swe/PS1 $B M$ chimeras is shown on the right. Data are means \pm SEM. At least 5 mice per group were examined. $B$, Phagocyte engraftment from the hematopoietic compartment requires irradiation of the brains of AD transgenic mice. Ramified GFP- and lba-1-expressing cells were examined 7 months after BMC transfer. Immunohistochemistry for Iba-1 (blue, left; red, right), A $\beta$ deposits (red), GFP fluorescence (green), and DAPI staining of nuclei (blue) in cortical and hippocampal sections from unprotected and protected CCR2 ${ }^{+/+}$GFP $\rightarrow A P P^{5 w e / P S 1}$ BM chimeras reveals that BM-derived $\left(\mathrm{GFP}^{+}\right) \mathrm{lba}-1^{+}$mononuclear phagocytes (arrows) are exclusively found in unprotected AD brains, whereas nonirradiated (protected) brains are devoid of parenchymal ramified GFP ${ }^{+}$cells. Endogenous host microglia are lba- $1^{+} \mathrm{GFP}^{-}$(arrowheads). Scale bars, $30 \mu \mathrm{m}$. C-E, Semiquantitative analysis of regional myeloid cell engraftment (GFP ${ }^{+} \mathrm{Iba}-1^{+}$cells) in the brain (cortex and hippocampus) ( $\boldsymbol{C}$ and spinal cord ( $\boldsymbol{D}$ ) of total-body irradiated (unprotected) and brain-shielded (protected) $C\left(R 2^{+/+}{ }_{\text {GFP } \rightarrow A P P \text { swe/PS1 }}\right.$ BM chimeras. Engraftment of BM-derived mononuclear cells strictly depends on irradiation of the nervous tissue in AD transgenic mice. The percentage of plaques surrounded by GFP ${ }^{+}$mononuclear cells in the conditioned brains is shown in $\boldsymbol{E}$. Data are means \pm SEM from at least three sections per animal and at least 5 mice per group. n.d., Not detectable.

unprotected CCR2 $2^{+/+}$GFP $\rightarrow$ APP ${ }^{\text {swe/PS1 }}$ mice $(13.9 \pm 4.3$ cells/ $\mathrm{mm}^{2}$ in the hippocampus and $12.7 \pm 2.5$ cells $/ \mathrm{mm}^{2}$ in the cortex), whereas protected $C C R 2^{+/+} G F P \rightarrow A P P^{\text {swe/PS1 }}$ mice were completely devoid of any engrafted cells in the brain parenchyma and around amyloid plaques (Fig. 2C). However, engraftment of GFP-labeled cells in protected animals occurred in the nonshielded spinal cord of these animals, underscoring that conditioning by irradiation is a prerequisite for hematopoietic cell entry into the CNS parenchyma (Fig. 2D). To examine whether the turnover of perivascular macrophages (PVMs) also depends on irradiation, we examined the presence of $\mathrm{GFP}^{+}$cells around blood vessels in the brains of $\mathrm{AD}$ transgenic mice. As expected from our previous work (Bechmann et al., 2001), donor-derived cells with elongated cell bodies and bipolar shape were detected around blood vessels in both protected and unprotected BM chimeras (data not shown). Quantitative examination revealed robust engraftment of donor-derived PVMs in the perivascular spaces that was not significantly decreased in the protected individuals $(7.1 \pm 1.9$ cells/section compared with $8.9 \pm 2.5$ cells/section in unprotected samples). To assess the capacity of transferred BM cells to migrate to amyloid plaques, we determined the percentage of $\mathrm{A} \beta$ deposits surrounded by $\mathrm{GFP}^{+}$ cells in unprotected $C C R 2^{+/+}$GFP $\rightarrow A P P^{\text {swe/PSI }}$ mice. Again, only a minority of amyloid plaques in the hippocampus were 

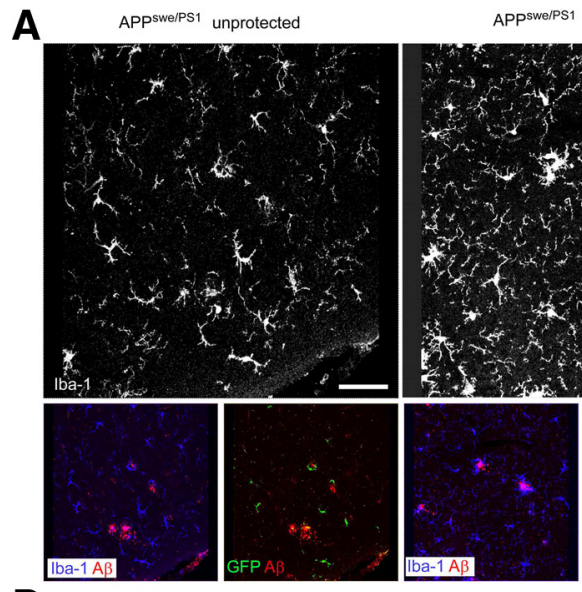

D

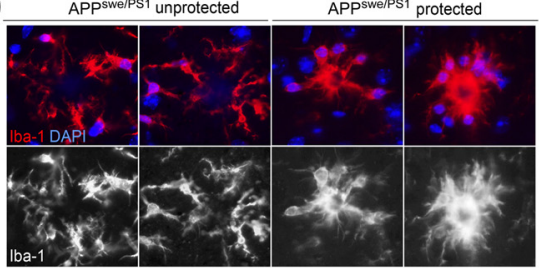

$\mathbf{F}$

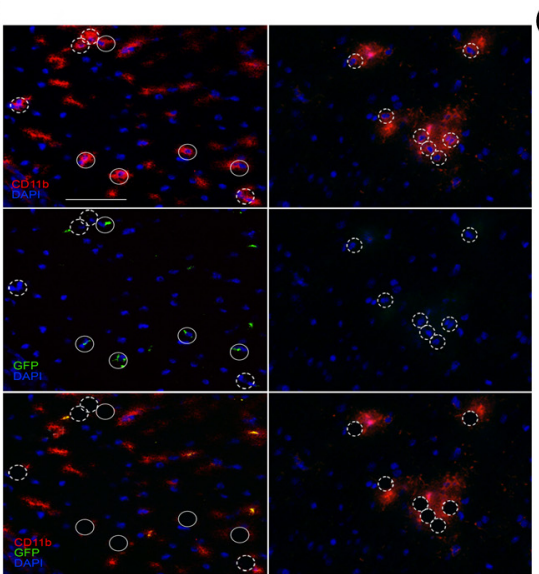

G

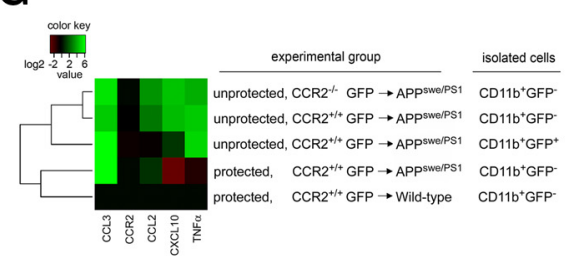

Figure 3. Irradiation changes the network of microglia, alters their morphology, and shapes the local inflammatory milieu. $A$, Iba- 1 immunoreactivity (white) reveals dramatic changes of the microglia network upon irradiation in unprotected $C\left(R 2^{+/+} \mathrm{GFP} \rightarrow\right.$

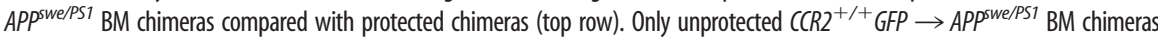
(APPswe/PS1 unprotected) contain GFP (green) lba-1-immunoreactive (blue) phagocytes, which partially surround $A \beta$ plaques (red) (bottom row). $B$, Quantification of $\mathrm{lba}-1^{+}$cells per $\beta$-amyloid plaque indicates a significant reduction of plaque-associated lba- ${ }^{+}$ microglia/macrophages in unprotected $C C R 2^{+/+}$GFP $\rightarrow A P P^{\text {swe/PS1 }}$ BM chimeras (APP ${ }^{\text {swe/PS1 }}$ unprotected, black bars) compared with protected chimeras (APPSwe/PS1 protected, white bars) independent of the plaque size. Data are means \pm SEM from at least three sections per animal and at least 5 mice per group. ${ }^{*} p<0.05$ statistical significance. C, Quantitative real-timePCRanalysis of CXCL10, CCL3, CCR2, and scavenger AmRNA expression in the brains of unprotected $C C R 2^{+/+}$GFP $\rightarrow A P P^{\text {swe/PS1 }}$ BM chimeras (black bars) compared with protected chimeras (white bars). Data are means \pm SEM from at least 5 mice animals per group. ${ }^{*} p<0.05$ statistical significance. $D$, Morphology of microglia/macrophages surrounding $\beta$-amyloid plaques in the brain. In unprotected $C\left(R 2^{+/+}\right.$GFP $\rightarrow$ APP swe/PS1 BM chimeras (APPswe/PS1 unprotected), Iba-1-immunoreactive microglia/macrophages (red) are dystrophic and dissociated from the plaque (left). In contrast, lba-1 ${ }^{+}$microglia/macrophages in protected $C C R 2^{+/+}$GFP $\rightarrow$ APP ${ }^{\text {swe/PS1 }}$ BM chimeras (APPswe/PS1 protected) cluster in and around the plaque and extend cellular protrusions into the core of the plaque (right). Nuclear DAPI staining in blue. $\boldsymbol{E}$, Morphology of Iba-1immunoreactive microglia/macrophages in the brain at sites distant from $\beta$-amyloid deposits. In unprotected $C C R 2^{+/+}{ }^{\text {GFP } \rightarrow A P P \text { swe/PS1 }}$ BM chimeras (left), Iba-1-immunoreactive microglia/macrophages (red) have enlarged cell bodies with short and spiny processes compared with the protected condition (right). Nuclear DAPI staining in blue. $\boldsymbol{F}$, Laser microdissection of CD11b ${ }^{+} \mathrm{GFP}^{-}$endogenous microglia and $\mathrm{CD} 11 \mathrm{~b}^{+} \mathrm{GFP}^{+}$engrafted macrophages from the hippocampus of unprotected and protected $C\left(R 2^{+/+} \mathrm{GFP} \rightarrow A P P^{\text {swe/PS1 }} \mathrm{BM}^{\mathrm{Chi}-}\right.$ meras. Nuclear staining with DAPI is shown in blue, CD11b immunoreactivity in red (top), and GFP expression in green (middle). The bottom shows the overlay and indicates the results of microdissection. Closed circles indicate dissected endogenous microglia $\left(\mathrm{CD}_{11 b^{+}} \mathrm{GFP}^{-}\right.$), dashed circles indicate BM-derived macrophages $\left(\mathrm{CD}_{11 \mathrm{~b}}{ }^{+} \mathrm{GFP}{ }^{+}\right)$. Scale bar, $50 \mu \mathrm{m}$. G, Quantification of cytokine and chemokine mRNA expression in microdissected $\mathrm{CD} 11 \mathrm{~b}^{+} \mathrm{GFP}^{-}$and $\mathrm{CD} 11 \mathrm{~b}^{+} \mathrm{GFP}^{+}$microglia/macrophages under different experimental conditions. Data are presented as a heat map with a $\log _{2}$ scale (brown, downregulated; green, upregulated). Rows indicate experimental groups; columns represent particular genes. Each data point reflects the median expression value of a particular gene resulting from three to four individual mice, normalized to the mean expression value of the respective gene in $\mathrm{CD} 11 \mathrm{~b}{ }^{+} \mathrm{GFP}{ }^{-}$cells from protected wild-type recipients. clearly associated with donor-derived cells, whereas most $\mathrm{GFP}^{+}$cells were not located in proximity to $A \beta$ deposits (Fig. 2E).

In summary, our data provide strong evidence that the engraftment of myeloid cells in the brain parenchyma of AD transgenic mice does not occur normally during disease progression, but requires prior CNS conditioning to sufficiently attract BM cells. Furthermore, engrafted phagocytes were not primarily attracted by amyloid plaques in the brain parenchyma. In contrast, turnover of PVMs around vessels did not depend on irradiation.

\section{Brain conditioning alters the $\mathrm{CNS}$} milieu and mitigates $\mathrm{A} \boldsymbol{\beta}$ deposition in AD transgenic mice

Since irradiation of the CNS induces a tremendous and rapid gene regulation (Linard et al., 2004; François et al., 2006), we examined the structural and molecular consequences of irradiation on the brains of $A P P^{\text {swe }}$ PS1 mice. Thorough histopathological examination of brain sections from protected $C C R 2^{+/+} \mathrm{GFP} \rightarrow$ $A P P^{\text {swe } / P S 1}$ mice $\left(A P P^{\text {swe } / P S 1}\right.$ protected) revealed a dense network of Iba-1immunoreactive cells, which characterizes endogenous microglia under these experimental conditions (Fig. 3A). Microglia were densely packed and localized mainly around $\mathrm{A} \beta$ plaques. In sharp contrast to this situation, irradiation dramatically changed the morphology of Iba- $1^{+}$ cellular networks and the association of Iba- ${ }^{+}$cells with amyloid plaques in the brains of unprotected CCR $2^{+/+}$GFP $\rightarrow$ $A P P^{\text {swe } / P S 1}$ mice (APP $P^{\text {swe/PS1 }}$ unprotected) (Fig. 3A). BM-derived phagocytes expressing GFP and Iba-1 were now present in the brain, but endogenous $\mathrm{GFP}^{-} \mathrm{Iba}^{+}{ }^{+}$microglia appeared more separated and disintegrated from the local glial environment. In fact, quantitative measurements of Iba- $1^{+}$cells associated with amyloid plaques revealed a significant reduction in plaque-associated microglia/macrophages at 7 months after irradiation (Fig. 3B).

We next analyzed the whole brain for expression of chemoattractant factors known to be involved in the recruitment of myeloid cells, and the phagocyte scavenger $\mathrm{A}$ as the key microglial factor required for the clearance of insoluble $\mathrm{A} \beta$ (Fig. 3C). Notably, we observed significantly less CXCL10 and CCL3 mRNAs in the brains of unprotected $C C R 2^{+/+} G F P$ $\rightarrow A P P^{\text {swe/PS1 }}$ mice $\left(A P P^{\text {swe/PS1 }}\right.$ unprotected) compared with the protected chimeras. Interestingly, CCR 2 mRNA 

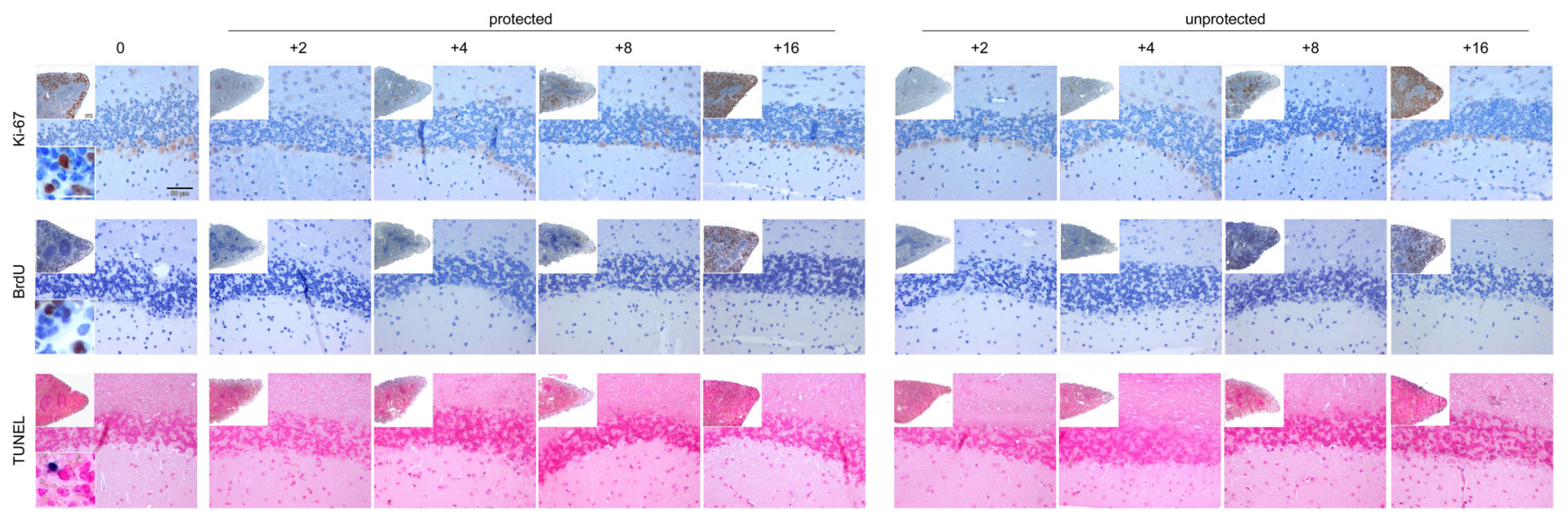

Figure 4. Absence of cell death and proliferation in the brain following irradiation and bone marrow transplantation. Tissue sections from the CNS of chimeric mice were stained at indicated time points after irradiation and BM transfer with antibodies against Ki-67 (TEC-3, DAK0, 1:20) and BrdU (in situ Detection Kit, BD PharMingen) for proliferation and TUNEL (Roche) for apoptotic cells. Spleens of chimeric mice were used as positive controls (insets). Representative pictures (cerebellum) from each experimental group ( $n=2-3$ mice) are shown.

expression was not altered, while gene expression of scavenger A was significantly higher in the brains of unprotected CCR2 $2^{+/+}$ $G F P \rightarrow A P P^{\text {swe/PS1 }}\left(A P P^{\text {swe/PS1 }}\right.$ unprotected) mice. These data clearly suggest robust long-term changes of the brain milieu, even several months after irradiation and BM transplantation.

Closer examination of microglia morphology by confocal microscopy uncovered striking changes of cellular organization (Fig. 3D). In protected CCR2 $2^{+/+} \mathrm{GFP} \rightarrow$ $A P P^{\text {swe/PSI }}$ mice (APP $P^{\text {swe/PS1 }}$ protected), Iba- $1^{+}$parenchymal cells showed typical microglial morphology with round to spindle-shaped somata and a distinct arborization pattern. Cells were located at the border of the amyloid plaques, and their processes reached into the core of the plaques. In contrast, microglia in the brains of unprotected $C C R 2^{+/+} G F P \rightarrow$ $A P P^{\text {swe/PSI }}$ mice (APP ${ }^{\text {swe/PSI }}$ unprotected)

were more dissociated from the $\mathrm{A} \beta$ deposits, with hardly any cellular processes reaching the center of the plaques. Similarly, parenchymal microglia that were not associated with amyloid plaques showed morphological signs of activation, namely retraction of cellular processes and rounding of the somata (Fig. 3E). Furthermore, activated microglia in unprotected $C C R 2^{+/+}$GFP $\rightarrow A P P^{\text {swe/PSI }}$ mice $\left(A P P^{\text {swe/PSI }}\right.$ unprotected) were covered by numerous spiny protrusions on the surface that could not be found in their counterparts in protected BM chimeras.

It has furthermore been proposed that BM-derived phagocytes are functionally different from endogenous microglia, e.g., by their increased immune gene expression (Simard et al., 2006). To determine whether endogenous microglia or BMderived phagocytes are the cellular sources of potentially detrimental mediators in $\mathrm{AD}$ and whether the individual gene profiles might be influenced by irradiation, we generated BM chimeras and performed single-cell microdissections on brain sections in situ (Fig. 3F). Immunostained serial sections were used to dissect $\mathrm{CD} 11 \mathrm{~b}^{+} \mathrm{GFP}^{-}$endogenous microglia and donor-derived

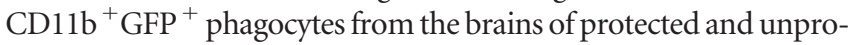
tected $C C R 2^{+/+}$GFP $\rightarrow A P P^{\text {swe/PSI }}$ BM chimeras by a pulsed UV
B
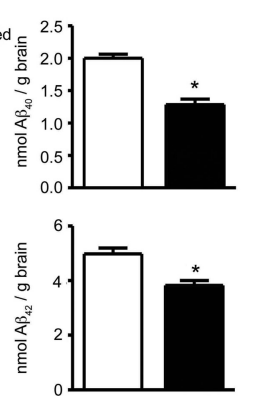

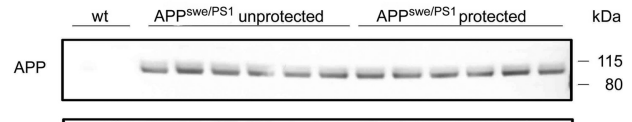

$\beta$-CTF $-\ldots-\ldots-\ldots-15$

$\mathrm{A} \beta$

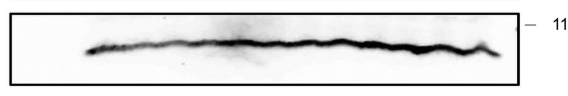

Figure 5. $A \beta$ deposition is reduced in $A D$ transgenic mice after brain irradiation and $B M C$ transplantation. $A$, Determination of the amounts of soluble and insoluble $A \beta_{1-40}$ and $A \beta_{1-42}$ by sandwich ELISA in brain lysates from protected (black bars) CCR2 ${ }^{+/+}$GFP $\rightarrow$ APP ${ }^{\text {sweePST }}$ BM chimeras 7 months after irradiation. Deposition insoluble, but not soluble $A \beta_{1-40}$ and $A \beta_{1-42}$ is significantly reduced in unprotected (brain-irradiated) $C C R 2^{+/+} G F P \rightarrow A P P^{\text {swe/PS }}$

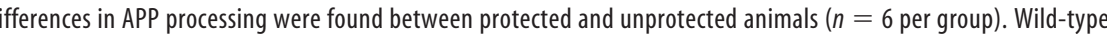
mice (wt) served as negative controls.

laser beam. Sections were counterstained with DAPI to facilitate the identification of individual cells. Cytokine mRNA expression was subsequently analyzed by quantitative RT-PCR (Fig. 3G). We found a $24.06 \pm 5.71$-fold increase of CXCL10 mRNA expression in

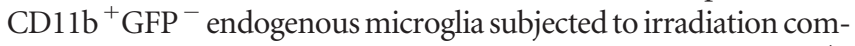
pared with $\mathrm{CD} 11 \mathrm{~b}^{+} \mathrm{GFP}^{-}$microglia from protected $C C R 2^{+/+}$ $G F P \rightarrow A P P^{\text {swe/PS1 }}$ mice, underscoring again the influence of prior brain conditioning. Note that CXCL10 mRNA expression was significantly decreased in whole brains of unprotected $C C R 2^{+/+} G F P \rightarrow A P P^{\text {swe/PSI }}$ mice compared with the protected chimeras (Fig. 3C), suggesting differential gene expression in microglia versus other types of brain cells. In contrast, CXCL10 mRNA levels were slightly downregulated in microglia from protected $C C R 2^{+/+} G F P \rightarrow A P P^{\text {swe/PS1 }}$ mice compared with protected $C C R 2^{+/+}$GFP $\rightarrow$ wild-type mice $(0.13 \pm 0.05$-fold compared with $1.74 \pm 0.54$-fold). CCL3 mRNA expression was

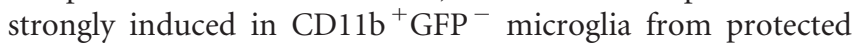
$C C R 2^{+/+}$GFP $\rightarrow A P P^{\text {swe/PSI }}$ mice compared with protected $C C R 2^{+/+} G F P \rightarrow$ wild-type mice (67.81 \pm 10.15 -fold compared with $1.19 \pm 0.28$-fold), indicating a disease-associated induction of this chemokine. Whereas CCL3 gene expression was largely unchanged by irradiation, CCL2 and TNF $\alpha$ transcripts were 

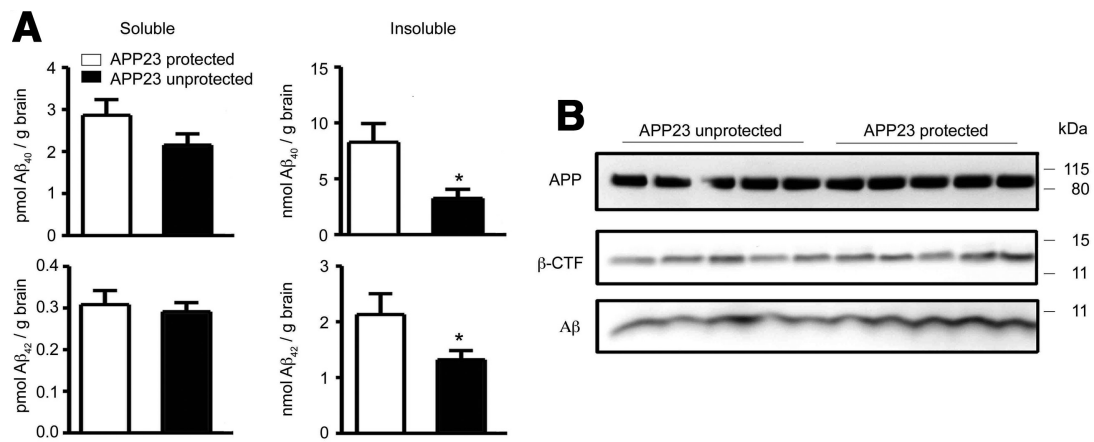

Figure 6. $A \beta$ deposition is reduced in $A D$ transgenic mice after brain irradiation and $B M$ transplantation. $A$, Determination of the amounts of soluble and insoluble $A \beta_{1-40}$ and $A \beta_{1-42}$ by sandwich ELISA in brain lysates from protected (white bars) and unprotected (black bars) CCR2 $2^{+/+}$GFP $\rightarrow A P P 23$ BM chimeras. Deposition of insoluble, but not soluble $A \beta_{1-40}$ and $A \beta_{1-42}$ is significantly reduced in unprotected (brain-irradiated) $C C R 2^{+/+}$GFP $\rightarrow$ APP23 BM chimeras. Data are means \pm SEM from 5 mice per group. ${ }^{*} p<0.05$ statistical significance. $B$, Immunoblot analysis of brain lysates from unprotected and protected $C C R 2^{+/+}$ GFP $\rightarrow$ APP23 BM chimeras for APP, $\beta$-CTF, and A $\beta$. No differences in APP processing were found between protected and unprotected animals ( $n=5$ per group).
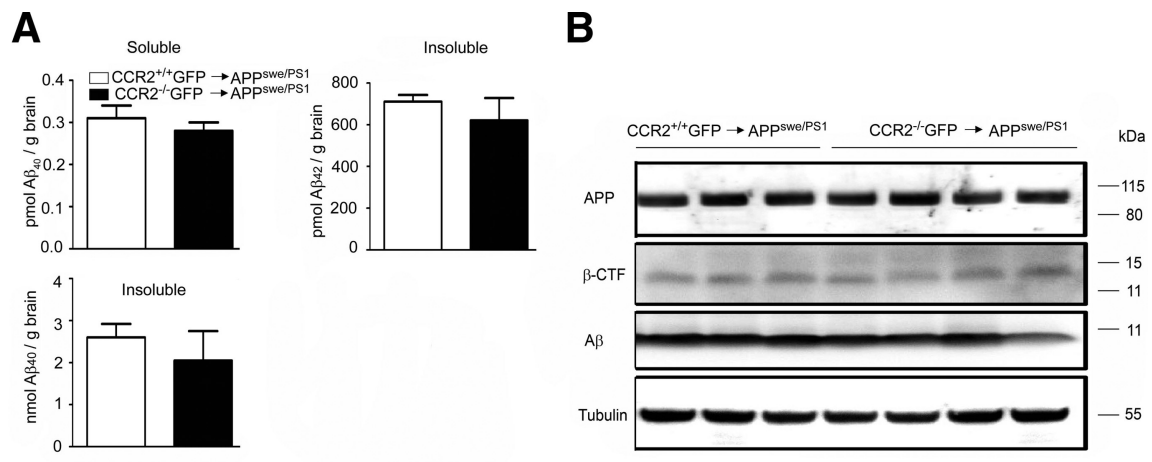

Figure 7. Parenchymal $A \beta$ load in the brains of $A D$ transgenic mice is independent from the presence of immigrating bone marrow-derived phagocytes. $A$, Determination of the amounts of soluble and insoluble $A \beta_{1-40}$ and $A \beta_{1-42}$ by sandwich ELISA in brain lysates from unprotected (brain-irradiated) CCR2 ${ }^{+/+}$GFP $\rightarrow A P P^{\text {Swe } P S 51}$ (white bars) and $C\left(R 2^{-1-}\right.$ GFP $\rightarrow$ APP ${ }^{\text {swe/PS1 }}$ (black bars) BM chimeric mice. A $\beta$ deposition is independent of the engraftment of donorderived phagocytes in the brain, which is significantly reduced in $C C R 2^{-/-}$GFP $\rightarrow A P P^{5 w e / P S 1}$ BM chimeras (see also Fig. $1 C, D)$. B, Immunoblot analysis of brain lysates from $C C R 2^{+/+}$GFP $\rightarrow A P P^{\text {swe/PS1 }}$ and $C C R 2^{-/-}$GFP $\rightarrow A P P^{\text {swe/PS1 }}$ BM chimeric mice for APP, $\beta$-CTF, and A $\beta$. No differences in APP processing were found between the groups $(n=3-4$ per group). Tubulin served as loading control.

always induced in $\mathrm{CD}_{1} 1 \mathrm{~b}^{+}$cells from irradiated brains. In contrast, CCR2 mRNA expression in microglia/phagocytes was influenced neither by disease nor by brain irradiation.

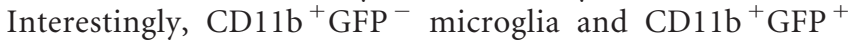
BM-derived phagocytes from unprotected $C C R 2^{+/+} \mathrm{GFP} \rightarrow$ $A P P^{\text {swe/PSI }}$ mice had different levels of CCL2 and CXCL10 mRNA expression (CCL2 mRNA, $6.70 \pm 2.20 \mathrm{in} \mathrm{CD11b}^{+} \mathrm{GFP}^{-}$and $0.72 \pm$ 0.24 in CD11b $^{+} \mathrm{GFP}^{+}$cells; CXCL10 mRNA, $20.89 \pm 7.24$ in

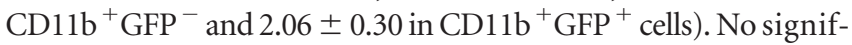
icant differences in cytokine and chemokine gene expression were observed between $\mathrm{CD}_{11} \mathrm{~b}^{+} \mathrm{GFP}^{-}$microglia isolated from $C C R 2^{+/+} G F P \rightarrow A P P^{\text {swe/PSI }}$ and $C C R 2^{-/-}$GFP $\rightarrow A P P^{\text {swe/PSI }}$ mice. The chemokine and cytokine gene expression changes induced in microglia by irradiation coincide with the morphological changes observed in brain sections from unprotected BM chimeras, but they do not necessarily overlap with the pattern of gene regulation observed in whole-brain lysates. However, the results strongly suggest differential functional properties of endogenous microglia and BM-derived mononuclear cells.
To examine whether irradiation of the CNS induces cell death or proliferation of parenchymal cells, histopathological changes following irradiation were investigated in more detail (Fig. 4). Unprotected BM chimeras received intraperitoneal injections of $100 \mu \mathrm{g}$ of BrdU every second day starting on day 0 after irradiation, and the brains were analyzed $0,2,4,8$, and $16 \mathrm{~d}$ post-irradiation. We did not observe any apoptotic TUNEL ${ }^{+}$ or proliferating $\mathrm{Ki}-67^{+}$(TEC-3) or $\mathrm{BrdU}^{+}$ cells in the cerebellum, suggesting that these events are obviously not induced when cytokine mRNA levels peak in the brains following irradiation, as described previously (Mildner et al., 2007).

To determine whether irradiationinduced changes of brain homeostasis affect $A \beta$ burden and APP processing, we examined $\beta$-amyloid content in brain lysates from protected and unprotected $C C R 2^{+/+} G F P \rightarrow A P P^{\text {swe/PS1 }}$ BM chimeric mice (Fig. 5A). Surprisingly, the amount of insoluble $\mathrm{A} \beta_{1-40}$ and $\mathrm{A} \beta_{1-42}$ was significantly reduced after brain irradiation, while soluble $A \beta_{1-40}$ and $A \beta_{1-42}$ remained unchanged. Importantly, the levels of full-length APP and $\beta$-CTF were comparable between both groups, suggesting that brain irradiation might inhibit the degradation/clearance of fibrillar insoluble $\mathrm{A} \beta_{1-40}$ and $\mathrm{A} \beta_{1-42}$ by mononuclear phagocytes, rather than altering the processing of APP (Fig. 5B).

To confirm our findings in an alternative and less aggressive AD mouse model, we used APP23 mice (Fig. 6). In this transgenic line, APP gene expression is driven by the neuronal Thy-1 promoter, leading to a slower progression of $\mathrm{AD}$ pathology compared with $A P P^{\text {swe/PS1 }}$ mice. When $A P P 23$ mice were used as recipients of BM cells from $\beta$-actin-EGFP mice, some invading ameboid-like $\mathrm{GFP}^{+}$cells were found in the brains of unprotected $C C R 2^{+/+}$ $G F P \rightarrow A P P 23$ mice, while none were detected in protected $C C R 2^{+/+}$GFP $\rightarrow$ APP23 BM chimeras (data not shown). These results are in line with the findings of Stalder et al. (2005), and indicate that hematopoietic cells also engraft in response to cerebral amyloidosis in this single transgenic $\mathrm{AD}$ model. In analogy to our results in $A P P^{\text {swe/PSI }} \mathrm{BM}$ chimeric mice, unprotected $C C R 2^{+/+}$ GFP $\rightarrow$ APP23 mice contained significantly less insoluble $\mathrm{A} \beta_{1-40}$ and $\mathrm{A} \beta_{1-42}$ in the brain compared with protected $C C R 2^{+/+}$GFP $\rightarrow$ APP23 mice, while the levels of soluble $\mathrm{A} \beta_{1-40}$ and $\mathrm{A} \beta_{1-42}$, and APP and $\beta$-CTF were unchanged (Fig. 6). Stereological analysis revealed no significant differences in $\beta$-amyloid plaque load in the neocortex and hippocampus of protected versus unprotected $C C R 2^{+/+}$GFP $\rightarrow$ APP23 mice (data not shown).

Together, these results underscore the broad impact of brain irradiation before BM transplantation, which induces considerable and long-lasting morphological, genetic, and functional changes of brain cells, including microglia. 
BM-derived mononuclear phagocytes do not modulate parenchymal A $\beta$ load in CCR2-deficient chimeras

It has been proposed that BM-derived microglia are critical in restricting senile plaque formation in $\mathrm{AD}$ mouse models due to improved migration and increased phagocytosis compared with endogenous microglia (Simard et al., 2006). To establish whether BM-derived phagocytes are beneficial or detrimental to $\mathrm{AD}$ pathogenesis, we generated $\mathrm{BM}$ chimeras specifically lacking donor-derived cells in their brains. For this purpose, CCR2 $2^{+/+} G F P \rightarrow$ $A P P^{\text {swe/PS1 }}$ and $C C R 2^{-/-}$GFP $\rightarrow A P P^{\text {swe/PS1 }}$ mice were generated, which were total body irradiated before BM transplantation to condition the brains for potential myeloid cell entry. However, as we have shown before, unprotected CCR2 $2^{-/-}$ $G F P \rightarrow A P P^{\text {swe/PS1 }}$ mice lacked significant numbers of engrafted GFP ${ }^{+} \mathrm{Iba}_{-}{ }^{+}$cells compared with wild-type donors despite a comparable degree of blood chimerism (Fig. 1C). Surprisingly, determination of the levels of soluble and insoluble $\mathrm{A} \beta_{1-40}$ and $\mathrm{A} \beta_{1-42}$ in the brains of $C C R 2^{+/+}$ $G F P \rightarrow A P P^{\text {swe/PS1 }}$ and $C C R 2^{-/-}$GFP $\rightarrow$ $A P P^{\text {swe/PS1 }}$ mice did not reveal any significant differences (Fig. 7A). Moreover, immunoblot analyses of brain lysates revealed similar quantities of APP, $\beta$-CTF, and $A \beta$ (Fig. $7 B$ ). Thus, our results suggest that BM-derived phagocytes can be targeted to parenchymal $\beta$-amyloid plaques in a CCR2-dependent manner, but changes of $\mathrm{A} \beta$ load depend on irradiation-induced changes, such as activation of endogenous brain $\mathrm{A} \beta$ clearance or increased brain-toblood efflux of $A \beta$, rather than reduced amyloidogenic APP metabolism or the recruitment of BM-derived phagocytes to parenchymal $\mathrm{A} \beta$ deposits.

\section{Perivascular macrophages in AD transgenic mice clear $A \beta$ in a CCR2-dependent manner}

To further explore the role of hematopoietic cells in $\mathrm{A} \beta$ clearance, we took advantage of transgenic $T g 2576$ (APP ${ }^{\text {swe }}$ ) mice expressing the 695 aa isoform of human APP, a well established model for a nonaggressively progressing disease with established CCR2 dependency (El Khoury et al., 2007).

To generate $A P P^{\text {swe }}$ mice deficient in CCR2, we bred $A P P^{\text {swe }}$ mice with $C C R 2^{-1-}$ mice and examined the survival times (Fig. 8A). As already described, $\mathrm{APP}^{\text {swe }}$ mice deficient in CCR2 $\left(A P P^{\text {swe }} C C R 2^{-/-}\right)$had a marked increase in mortality compared with wild-type $C C R 2^{+/+}, C C R 2^{-/-}$, and $A P P^{\text {swe }}$ mice
A

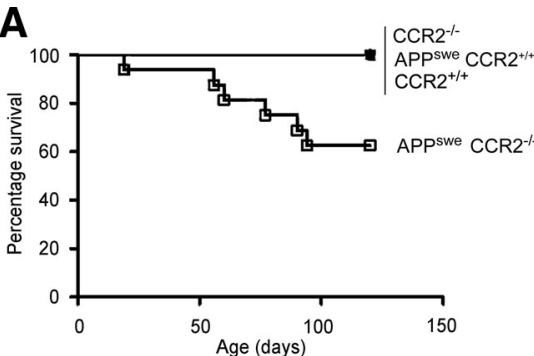

C

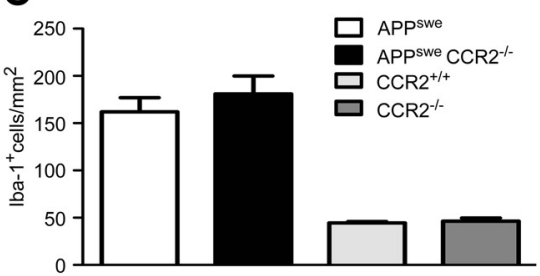

E

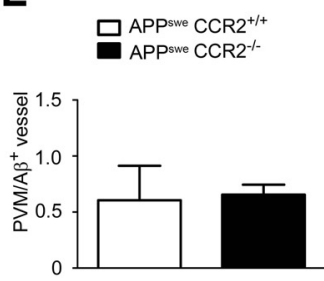

G
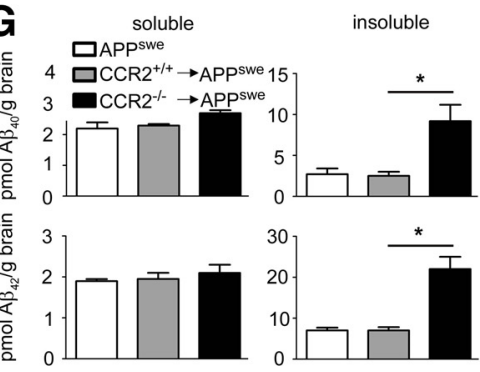

B

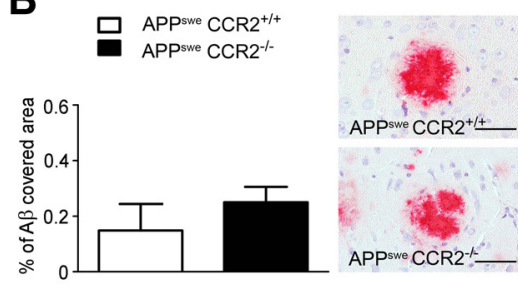

D

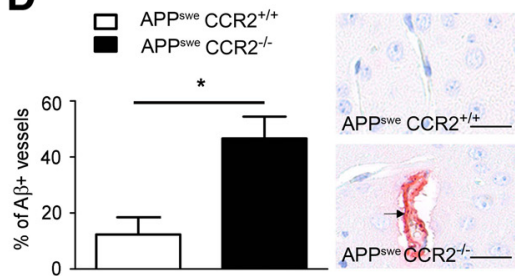

F
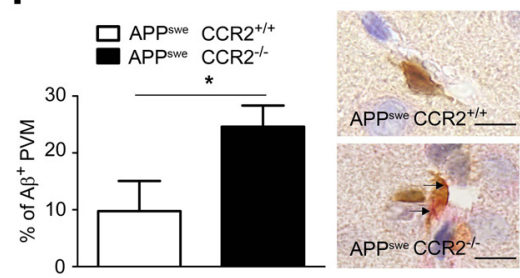

H
Figure 8. Perivascular macrophages in $A D$ transgenic mice clear $A \beta$ in a CCR2-dependent manner. $A$, Expression of CCR2 determines the survival of $A P P^{\text {swe }}$ mice. Survival curves of wild-type $C\left(R 2^{+/+}, C C R 2^{-/-}, A P P^{5 w e} C\left(R 2^{+/+}\right.\right.$, and $A P P^{\text {swe }} C\left(R 2^{-/-}\right.$mice are shown. In each experimental group at least 20 mice were used. $B$, Immunohistochemistry with an antibody against $A \beta$ reveals no difference in the relative area covered by $A \beta$ in the cortex of $A P P^{\text {swe }} C C R 2^{+/+}$and $A P P^{\text {swe }} C C R 2^{-/-}$mice. Data are means \pm SEM from at least 3 sections per animal and at least 3 mice per group. Representative immunostained sections are shown on the right. Scale bars, $100 \mu m$. C, Semiquantitative analysis of lba-1-immunoreactive cells in the brain reveals normal proliferation of microglia in the absence of CCR2. The number of $\mathrm{lba}-1^{+}$microglia/macrophages is significantly increased in the brains of $A P P^{\text {swe }}\left(C R 2^{+/+}\right.$(white bar, $\left.n=4\right)$ and $A P P^{\text {swe }}$ $C C R 2^{-1-}$ mice (blackbar, $\left.n=4\right)$ compared with $C C R 2^{+/+}$(light graybar, $\left.n=3\right)$ and $C\left(R 2^{-1-}\right.$ mice (dark gray bar, $\left.n=4\right)$, respectively. The number of lba- $1^{+}$cells is not different between $A P P^{\text {swe }} C\left(R 2^{+/+}\right.$and $A P P^{\text {swe }} C\left(R 2^{-/-}\right.$mice, or between $C\left(R 2^{+/+}\right.$and $C\left(R 2^{-/-}\right.$ mice. Data are means \pm SEM from at least 3 sections per animal and at least 3 mice per group. $D$, Immunohistochemistry with an antibody against $A \beta$ reveals a significant increase in the percentage of blood vessels containing $\beta$-amyloid in the cortex of $A P P^{\text {swe }}\left(C R 2^{-1-}\right.$ compared with $A P P^{\text {swe }} C\left(R 2^{+/+}\right.$mice. Data are means \pm SEM from at least 3 sections per animal and at least 3 mice per group. Asterisk indicates statistical significance $(p<0.05)$. Representative immunostained sections are shown on the right, and the arrow indicates vascular $A \beta$ accumulation. Scale bars, $50 \mu \mathrm{m}$. $\boldsymbol{E}$, Absence of CCR2 does not change the number of lba- ${ }^{+}$PVMs per $A \beta$-containing blood vessel. Semiquantitative analysis reveals the same number of PVMs in $A P P^{\text {swe }} C C R 2^{+/+}$as in $A P P^{\text {swe }} C C R 2^{-/-}$mice. Data are means \pm SEM from at least 3 sections per animal and at least 3 mice per group. $F, C C R 2$ deficiency increases the percentage of perivascular macrophages, which accumulate $A \beta$. Semiquantitative analysis was performed on at least 3 sections per animal and at least 3 mice per group $\left(A P P^{\text {swe }} C\left(R 2^{+/+}\right.\right.$and $A P P^{\text {swe }} C\left(R 2^{-/-}\right.$mice). Data are means \pm SEM. ${ }^{*} p<0.05$ statistical significance. Representative immunostained sections are shown on the right. $A \beta^{+} \mathrm{lba}-1^{+} \mathrm{PVMs}$ were visualized by double immunohistochemistry ( $A \beta$ in red, lba- 1 in brown). The arrows point to a $\beta$ deposition in PVMs. Scale bars, $20 \mu \mathrm{m}$. G, Determination of the amounts of soluble and insoluble $A \beta_{1-40}$ and $A \beta_{1-42}$ by sandwich ELISA in brain lysates from nontransplanted $A P P^{\text {swe }}$ mice (white bars), and from protected, i.e., brain shielded from irradiation, $\mathrm{CCR}^{+/+}$GFP $\rightarrow$ APPswe (gray bars) and CCR2 ${ }^{-/-}$GFP $\rightarrow$ APPswe (black bars) BM chimeric mice 7 months after transplantation. Deposition of insoluble, but not soluble $A \beta_{1-40}$ and $A \beta_{1-42}$ is significantly increased in $A P P^{\text {swe }}$ mice transplanted with CCR2-deficient BMCs. Data are means \pm SEM from at least 3 mice per group. ${ }^{*} p<0.05$ statistical significance. $\boldsymbol{H}$, Immunoblot analysis of brain lysates from $A P P^{5 \text { swe }}$ mice, and from protected $C C R 2^{+/+}$GFP $\rightarrow A P P^{\text {swe }}$ and $C C R 2^{-/-}$GFP $\rightarrow A P P^{\text {swe }}$ BM chimeric mice for $A P P$, $\alpha$ - and $\beta$-CTF, and A $\beta$. A $\beta$ accumulation is enhanced in APPswe mice transplanted with CCR2-deficient BMCs, whereas APP processing is unchanged ( $n=3-5$ per group). 
$(p<0.05)$. By $120 \mathrm{~d}$ of age, $38 \%$ of $A P P^{s w e} C C R 2^{-1-}$ had died, compared with $100 \%$ survival in the other groups of mice. Interestingly, even $A P P^{\text {swe }}$ mice had normal survival rates up to this time point. These data confirm that the presence of the chemokine receptor CCR2 modulates pathogenicity in this $\mathrm{AD}$ mouse model.

To determine whether the increased mortality in $A P P^{\text {swe }}$ $C C R 2^{-1-}$ mice was associated with elevated brain parenchymal $\beta$-amyloid deposits, we performed immunohistochemistry with antibodies against $\mathrm{A} \beta$. Similar amounts of parenchymal $\mathrm{A} \beta$ deposition were found in the brains of aged $A P P^{\text {swe }} C C R 2^{-1-}$ mice and agematched $A P P^{\text {swe }} C C R 2^{+/+}$control mice (Fig. $8 B$ ).

Both microglia and BM-derived phagocytes have been implicated in the clearance of $A \beta$ from the brain (Bard et al., 2000). However, the mechanisms by which mononuclear phagocytes are recruited into $\mathrm{AD}$ brains are not known. CCR2 is the main chemokine receptor for CCL2 and mediates CCL2-induced leukocyte chemotaxis (Mildner et al., 2007; Prinz and Priller, 2010) Since El Khoury et al. (2007) suggested that CCR2 deficiency might affect microglia accumulation in $A P P^{\text {swe }}$ mice, we performed immunohistochemical stainings for the well established macrophage/microglia marker, Iba-1, and quantified Iba-1immunoreactive cells in the brains of $A P P^{\text {swe }} C C R 2^{-/-}$, $A P P^{s w e} C C R 2^{+/+}, C C R 2^{-/-}$, and CCR2 ${ }^{+/+}$mice (Fig. 8C). As expected, diseased $A P P^{\text {swe }} C C R 2^{-/-}$and $A P P^{\text {swe }} C C R 2^{+/+}$animals exhibited more $\mathrm{Iba}^{+}{ }^{+}$cells per square millimeter than did $C C R 2^{-/-}$and $C C R 2^{+/+}$mice. Surprisingly, both $A P P^{\text {swe }} C C R 2^{-1-}$ and $A P P^{\text {swe }} C C R 2^{+/+}$mice had comparable numbers of Iba- $1^{+}$cells in the brain $\left(A P P^{\text {swe }} C C R 2^{-/-}, 181.0 \pm\right.$ 18.9 cells $/ \mathrm{mm}^{2}$; $A P P^{\text {swe }} C C R 2^{+/+}, 162.1 \pm 15.0$ cells $/ \mathrm{mm}^{2}$ ), clearly pointing to a redundant role of CCR2 for microglia recruitment and accumulation in $\mathrm{AD}$. This finding is in contrast with the findings of El Khoury et al. (2007). However, CCR2 $2^{-1-}$ and CCR2 $2^{+1+}$ mice also contained similar numbers of Iba- $1^{+}$ cells in the brain $\left(C C R 2^{-/-}, 44.0 \pm 1.4\right.$ cells $/ \mathrm{mm}^{2}$; CCR2 ${ }^{+/+}$, $46.1 \pm 3.9$ cells $\left./ \mathrm{mm}^{2}\right)$.

$A P P^{\text {swe }} C C R 2^{-/-}$mice show enhanced $\beta$-amyloid deposition around blood vessels, a situation known as CAA (El Khoury et al., 2007). We confirmed these findings by A $\beta$ immunohistochemistry (Fig. $8 D$ ). In $A P P^{\text {swe }} C C R 2^{-/-}$mice, $46.6 \pm 7.8 \%$ of all cortical vessels showed $\mathrm{A} \beta$ deposits compared with $12.3 \pm 6.2 \%$ in $A P P^{\text {swe }} C C R 2^{+/+}$mice. We therefore postulated that the absence of CCR2 leads to increased A $\beta$ accumulation in small blood vessels, possibly leading to intracerebral hemorrhages and premature death. In search of a potential mechanism, we asked whether the homeostasis and turnover of PVMs might be dependent on the presence of CCR2. To this end, we performed double immunohistochemistry for Iba-1 as macrophage marker and for GFAP to visualize the astrocyte end feet lining the glia limitans on brain sections from $C C R 2^{-/-}$and $C C R 2^{+/+}$mice (data not shown). Semiquantitative evaluation revealed a similar amount of PVMs regardless of the genotype, namely $14.1 \pm 2.8 \mathrm{Iba}-1^{+} \mathrm{PVMs} /$ section localized below the glia limitans in $C C R 2^{+/+}$mice and $13.6 \pm 1.7$ Iba- $1^{+}$PVMs/section in normal CCR2 $2^{-/-}$mice. To determine whether $C C R 2^{-/-}$mononuclear phagocytes might have a defect in their ability to migrate to cerebrovascular $\mathrm{A} \beta$ deposits, we next compared the number of Iba- $1^{+}$PVMs around $\mathrm{A} \beta^{+}$vessels in $120-\mathrm{d}-$ old $A P P^{\text {swe }} C C R 2^{-/-}$and $A P P^{\text {swe }} C C R 2^{+/+}$mice (Fig. $8 E$ ). The number of Iba- $1^{+}$PVMs per $A \beta$-containing vessel was independent of CCR2 expression, suggesting that CCR2 plays a redundant role in PVM recruitment to cerebrovascular $\mathrm{A} \beta$ deposits.

Since cerebrovascular $A \beta$ levels are mainly regulated by transport processes that shuttle $\mathrm{A} \beta$ across the blood-brain barrier
A
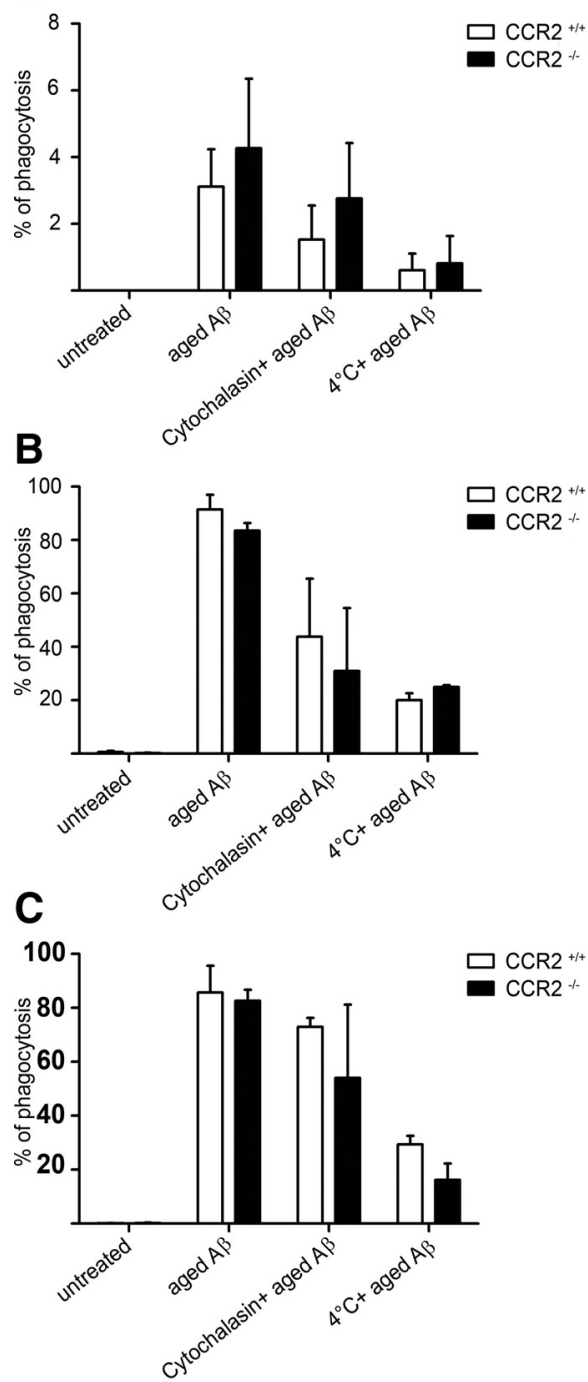

Figure 9. In vitro phagocytosis of $A \beta_{1-42}$ is unchanged in the absence of $C C R 2 . A, B$, Phagocytosis of aged $5^{\prime}-F A M A \beta_{1-42}$ by ex vivo isolated adult microglia $(A)$ and bone marrow-derived macrophages (BMDM) (B) from $C\left(R 2^{-/-}\right.$mice (black bars) and $C C R 2^{+/+}$mice (white bars) as measured by flow cytometry $6 \mathrm{~h}$ after aged $5^{\prime}$-FAM amyloid $\beta_{1-42}$ challenge. $C$, Addition of recombinant murine $C(\mathrm{CL} 2(10 \mathrm{ng} / \mathrm{ml})$ has no influence on $A \beta$ phagocytosis in BMDM. Data are means \pm SEM from 3 independent experiments with at least 3 mice per group.

(BBB) (Mucke, 2009), CCR2 may play an important role in A $\beta$ clearance by PVMs. We determined the percentage of PVMs that incorporated $\mathrm{A} \beta$ by double immunohistochemistry for Iba- 1 and $\mathrm{A} \beta$ (Fig. $8 F$ ). A $\beta$-containing $\mathrm{Iba}-1^{+}$PVMs were significantly more frequent in $A P P^{\text {swe }} C C R 2^{-/-}$mice compared with $A P P^{\text {swe }} C C R 2^{+/+}$mice $\left(A P P^{\text {swe }} C C R 2^{-/-}, 24.6 \pm 3.8 \mathrm{cells} / \mathrm{mm}^{2}\right.$; $A P P^{\text {swe }} C C R 2^{+/+}, 9.8 \pm 5.3$ cells $\left./ \mathrm{mm}^{2}\right)$. Thus, our data suggest that CCR2 deficiency affects $\mathrm{A} \beta$ clearance/transport by mononuclear phagocytes associated with blood vessels, but not by parenchymal microglia in AD transgenic mice.

To restrict CCR2 expression in $\mathrm{APP}^{\text {swe }}$ mice to the radioresistant vascular compartment, we generated protected BM chimeric mice. Brain shielding in these mice still allows for sufficient exchange of PVMs, while the entry of mononuclear phagocytes into the brain parenchyma is prevented. To test whether CCR2 deficiency in the periphery, including PVMs, induces a change in cerebral $\mathrm{A} \beta$ accumulation, we analyzed protected $\mathrm{CCR} 2^{-/-} \rightarrow$ $A P P^{\text {swe }}$ and $C C R 2^{+/+} \rightarrow A P P^{\text {swe }}$ mice at 7 months after BM trans- 
plantation (Fig. 8G,H). Notably, amyloid burden was dramatically increased in $C C R 2^{-/-} \rightarrow A P P^{\text {swe }}$ mice compared with $C C R 2^{+/+} \rightarrow A P P^{\text {swe }}$ and $A P P^{\text {swe }}$ mice. Biochemical analysis revealed an increase of both insoluble $A \beta_{1-40}$ and $A \beta_{1-42}$ in the brains of $C C R 2^{-/-} \rightarrow A P P^{\text {swe }}$ mice, whereas soluble $\mathrm{A} \beta_{1-40}$ and $\mathrm{A} \beta_{1-42}$ remained unchanged (Fig. $8 H$ ). To address steady-state APP metabolism, we also analyzed $\beta$-CTF and nonamyloidogenic CTF $(\alpha$-CTF), but we did not detect any differences between the genotypes (Fig. $8 H$ ).

To examine whether CCR2 $2^{-/-}$microglia and myeloid cells have a defect in their ability to phagocytose $A \beta$, we exposed the cells to FAM-labeled $\mathrm{A} \beta_{1-42}$ in vitro and performed flow cytometry (Fig. 9). We found that phagocytosis by adult microglia and bone marrow-derived macrophages was unchanged in the absence of CCR2. Accordingly, application of the CCR2 ligand, CCL2, did not modulate $A \beta$ uptake. Next, we examined whether CCR2 deficiency or synthesis of GFP might affect the expression of immune-related molecules and adhesion factors on adult microglia, circulating Ly$6 \mathrm{C}^{\text {hi }}$ monocytes, and macrophages using flow cytometry (Fig. 10). Baseline expression levels of CD11c, PSGL-1, and integrins $\alpha 4$ and $\beta 1$ were similar in all myeloid cell populations derived from $C C R 2^{+/+}, C C R 2^{+/+} G F P, C C R 2^{-/-}$, and $C C R 2^{-/-}$GFP mice, demonstrating that expression of neither CCR2 nor GFP influences the homeostatic baseline expression of immune molecules on the surface of microglia, monocytes, and macrophages.

Our results imply that peripheral macrophages, e.g., PVMs, rather than parenchymal microglia modulate $\beta$-amyloid deposition in the brains of $\mathrm{AD}$ transgenic mice by clearing $\mathrm{A} \beta$ in a CCR2-dependent fashion.

\section{Discussion}

Here, we describe and characterize a specific myeloid subpopulation of CCR2-expressing cells as the precursors of newly recruited tissue phagocytes in the brains of irradiated $\mathrm{AD}$ transgenic mice. Our findings are in line with the dominant role that MCP-1/CCL2, the ligand for CCR2, plays in chronic inflammation in the human AD brain (Janelsins et al., 2005; Sokolova et al., 2009). In mouse models of AD chimeras, CCR2 ${ }^{+}$myeloid cells are partially recruited to regions of $A \beta$ deposition, namely to senile plaques and the cerebrovascular compartment, where they exert differential functions. The recruitment of mononuclear phagocytes from the periphery to parenchymal $\beta$-amyloid plaques depended on CCR2 expression and conditioning of the brain (for example, irradiation), whereas Iba- $1^{+}$PVMs were recruited to vascular $\beta$-amyloid deposits in the absence of CCR2, but they needed this receptor for $\mathrm{A} \beta$ clearance. Thus, our data offer new insights into the mechanisms leading to the engraftment of BM/ blood-derived mononuclear phagocytes in the brains of chimeric $\mathrm{AD}$ transgenic mice, and suggest distinct spatiotemporal roles for specific myeloid subpopulations in disease pathogenesis.

Monocytes and tissue macrophages, such as microglia, are highly mobile immune effector cell populations with distinct functional features. Microglia already colonize the CNS during early embryogenesis, when they arise from hemangioblastic mesoderm and populate the developing neuroectoderm in rodents after embryonic day 8.5 (Alliot et al., 1999), whereas monocytes circulate in the blood during adulthood and cannot normally enter the brain, which is anatomically separated from the periphery by the BBB (Ransohoff and Perry, 2009). Early studies in irradiated rats using $\mathrm{MHC}$ mismatch as a marker of donor BM cells found only limited turnover of microglia with their peripheral myeloid counterparts (Hickey et al., 1992). However, more recent studies documented an early and rapid engraftment of BM-derived phagocytes in several models of neurodegenerative diseases, such as facial nerve axotomy (Priller et al., 2001), scrapie (Priller et al., 2006), the MPTP (1-methyl-4phenyl-1,2,3,6-tetrahydropyridine) model of Parkinson's disease (Kokovay and Cunningham, 2005), and Alzheimer's disease models (Malm et al., 2005; Stalder et al., 2005; Simard et al., 2006).

It is quite essential to note that the vast majority of BM chimera data addressing the functional impact and kinetics of newly recruited phagocytes versus endogenous microglia were obtained using total-body irradiation, without selective marrow-specific targeting of the myeloablative treatment. As we have demonstrated here, the involvement of the head during the irradiation procedure has a substantial impact on the local CNS environment. First, we observed substantial changes of the cellular networks of glial cells, as well as the morphology and localization of microglia in relation to $\beta$-amyloid plaques in $\mathrm{AD}$ transgenic mice. It was surprising to find that these alterations persist for several months after irradiation, indicating long-term effects of this conditioning regimen. Indeed, as we could show by singlecell microdissection followed by quantitative real-time PCR, $T N F \alpha, C C L 2$, and CXCL10 mRNA levels in microglia were greatly affected by irradiation. Subtle changes of BBB integrity or 
inactivation of repulsory signals following irradiation might also promote myeloid cell engraftment (Diserbo et al., 2002; Yuan et al., 2003). Finally, we cannot exclude any irradiation-induced neuronal damage that might cause distraction of microglia processes directly or indirectly.

CCL2 is induced not only by irradiation, but also during brain diseases, including AD (Ishizuka et al., 1997; Janelsins et al., 2005; Yamamoto et al., 2005; Prinz and Priller, 2010). Our results suggest that this chemokine might be involved in the recruitment of CCR2-expressing myeloid cells into the brains of AD transgenic mice. In line with this, transgenic overexpression of CCL2 in astrocytes of APP transgenic mice was associated with increased myeloid cell accumulation around plaques (Yamamoto et al., 2005). Here, we show for the first time that CCR2-expressing myeloid cells are the source of newly immigrated phagocytes in the brains of chimeric AD transgenic mice. However, in contrast to a previous report (Simard et al., 2006), we did not detect any effects of BM-derived phagocytes on parenchymal $\mathrm{A} \beta$ plaque load.

It has further been reported that CCR2 deficiency may hasten disease progression in $\mathrm{AD}$ transgenic mice, most likely as a result of impaired amyloid degradation by brain endogenous phagocytes, e.g., microglia (El Khoury et al., 2007). However, our data indicate that microglia proliferation and accumulation were unaltered in the absence of CCR2. Two other recent studies also question the involvement of microglia in the pathogenesis of AD. In vivo multiphoton imaging revealed that resident microglia are not important in the de novo formation of $\beta$-amyloid deposits in $\mathrm{AD}$ transgenic mice (Meyer-Luehmann et al., 2008). Moreover, ablation of the majority of parenchymal microglia using an inducible suicide gene approach in two mouse models of AD suggested that neither amyloid plaque formation and maintenance, nor amyloid-associated neuritic dystrophy depended on the presence of microglia (Grathwohl et al., 2009). Our findings are in line with a recent finding that CCR2 deficiency in $A P P^{\text {swe/PS1 }}$ mice provokes a rapid cognitive decline closely correlated with brain accumulation of soluble $\mathrm{A} \beta$ oligomers and a robust mRNA expression of TGF- $\beta 1, T G F-\beta-R 2$, and $C X_{3} C R 1$ in microglia (Naert and Rivest, 2011). Similar to our study, the authors further found no impaired microglia proliferation around $\mathrm{AD}$ plaques in the absence of CCR2. In sum, CCR2 has certainly complex functions in $\mathrm{AD}$ that go well beyond the control of the CNS immigration of defined myeloid subsets to a role in remodeling of $\mathrm{A} \beta$ deposition.

Our data further indicate the pathogenic role of another specialized subset of mononuclear phagocytes, namely PVMs, for $\mathrm{A} \beta$ clearance in the brains of $\mathrm{AD}$ transgenic mice. These phagocytes are located in the perivascular spaces, where they are important for immune surveillance and usually involved in the transport of $\mathrm{A} \beta$ across the BBB (Mucke, 2009). Recent experimental evidence highlighted the critical role of PVMs in the regulation of cerebral amyloid angiopathy (Hawkes and McLaurin, 2009). We found that the recruitment of PVMs from the $\mathrm{BM}$ to cerebrovascular $\mathrm{A} \beta$ deposits in $\mathrm{AD}$ transgenic mice occurred independent of CCR2. However, PVMs cleared $\mathrm{A} \beta$ from the brain in a CCR2-dependent manner. Previous results suggested that CCR2 deficiency abolished the chemotaxis of peritoneal macrophages to supernatants from $\mathrm{A} \beta$ stimulated macrophages (El Khoury et al., 2007). However, our data suggest that increased $A \beta$ levels in the brains of $A P P^{\text {swe }} C C R 2^{-/-}$mice were neither due to impaired recruitment of CCR2-deficient phagocytes from the blood into the brain, nor due to defects in the activation or proliferation of
CCR2-deficient microglia. Instead, our results imply a role for CCR2 in the clearance of $A \beta$ by PVMs. We speculate that PVMs from $C C R 2^{-/-}$mice might be inefficient in shuttling $\mathrm{A} \beta$ outside the brain along a CCL2-mediated vascular gradient. Thus, our study could provide the missing link between the landmark findings on the role of CCR2 and PVMs in mouse models of AD (El Khoury et al., 2007; Hawkes and McLaurin, 2009). Our results are also in line with earlier observations that microglia do not have the ability to clear $A \beta$ from the extracellular brain milieu, whereas peripheral macrophages can remove $A \beta$ in vivo by phagocytosis (Wisniewski et al., 1989, 1991).

What is the relevance of our findings for $\mathrm{AD}$ patients? There are several reports indicating that $\sim 60 \%$ of patients with AD have a disturbed BBB (Algotsson and Winblad, 2007; Bowman et al., 2007). Moreover, AD patients are generally aged and often have a history of cerebrovascular events caused by CAA, including ischemic insults (Koistinaho and Koistinaho, 2005). Therefore, it can be assumed that circulating mononuclear phagocytes may engraft in the brains in $\mathrm{AD}$ patients without conditioning by irradiation. This is relevant for myeloid cell-based gene therapy in AD. In fact, infusion of millions of genetically engineered BM-derived CD11 ${ }^{+}$cells into $A P P^{\text {swe/PS1 }}$ transgenic mice resulted in some parenchymal myeloid cell engraftment and modulation of amyloid deposition (Lebson et al., 2010). The impact of gene therapeutic approaches using myeloid precursors for CNS diseases has been highlighted in a mouse model of metachromatic leukodystrophy (Biffi et al., 2004), and more recently, in children with X-linked adrenoleukodystrophy (Cartier et al., 2009).

In conclusion, our results identified CCR $2{ }^{+}$mononuclear cells as the source of immigrating phagocytes in the brains of chimeric AD transgenic mice. Myeloid cells are recruited to sites of cerebral amyloidosis, namely parenchymal $\beta$-amyloid plaques and cerebrovascular $\mathrm{A} \beta$ deposits. Moreover, we defined the differential roles of these BM/blood-derived mononuclear phagocytes in the pathophysiology of $\mathrm{AD}$, and point to a dialectic function of myeloid cells inside and outside of the brain. It appears that the spatiotemporal role of phagocytes, i.e., when and where they are present and active, is a crucial issue.

\section{References}

Ajami B, Bennett JL, Krieger C, Tetzlaff W, Rossi FM (2007) Local selfrenewal can sustain CNS microglia maintenance and function throughout adult life. Nat Neurosci 10:1538-1543.

Akiyama H, Barger S, Barnum S, Bradt B, Bauer J, Cole GM, Cooper NR, Eikelenboom P, Emmerling M, Fiebich BL, Finch CE, Frautschy S, Griffin WS, Hampel H, Hull M, Landreth G, Lue L, Mrak R, Mackenzie IR, McGeer PL, et al (2000) Inflammation and Alzheimer's disease. Neurobiol Aging 21:383-421.

Algotsson A, Winblad B (2007) The integrity of the blood-brain barrier in Alzheimer's disease. Acta Neurol Scand 115:403-408.

Alliot F, Godin I, Pessac B (1999) Microglia derive from progenitors, originating from the yolk sac, and which proliferate in the brain. Brain Res Dev Brain Res 117:145-152.

Bard F, Cannon C, Barbour R, Burke RL, Games D, Grajeda H, Guido T, Hu K, Huang J, Johnson-Wood K, Khan K, Kholodenko D, Lee M, Lieberburg I, Motter R, Nguyen M, Soriano F, Vasquez N, Weiss K, Welch B, et al. (2000) Peripherally administered antibodies against amyloid betapeptide enter the central nervous system and reduce pathology in a mouse model of Alzheimer disease. Nat Med 6:916-919.

Bechmann I, Kwidzinski E, Kovac AD, Simbürger E, Horvath T, Gimsa U, Dirnagl U, Priller J, Nitsch R (2001) Turnover of rat brain perivascular cells. Exp Neurol 168:242-249.

Biffi A, De Palma M, Quattrini A, Del Carro U, Amadio S, Visigalli I, Sessa M, 
Fasano S, Brambilla R, Marchesini S, Bordignon C, Naldini L (2004) Correction of metachromatic leukodystrophy in the mouse model by transplantation of genetically modified hematopoietic stem cells. J Clin Invest 113:1118-1129.

Bowman GL, Kaye JA, Moore M, Waichunas D, Carlson NE, Quinn JF (2007) Blood-brain barrier impairment in Alzheimer disease: stability and functional significance. Neurology 68:1809-1814.

Cartier N, Hacein-Bey-Abina S, Bartholomae CC, Veres G, Schmidt M, Kutschera I, Vidaud M, Abel U, Dal-Cortivo L, Caccavelli L, Mahlaoui N, Kiermer V, Mittelstaedt D, Bellesme C, Lahlou N, Lefrère F, Blanche S, Audit M, Payen E, Leboulch P, et al. (2009) Hematopoietic stem cell gene therapy with a lentiviral vector in X-linked adrenoleukodystrophy. Science 326:818-823.

Chung H, Brazil MI, Soe TT, Maxfield FR (1999) Uptake, degradation, and release of fibrillar and soluble forms of Alzheimer's amyloid beta-peptide by microglial cells. J Biol Chem 274:32301-32308.

Diserbo M, Agin A, Lamproglou I, Mauris J, Staali F, Multon E, Amourette C (2002) Blood-brain barrier permeability after gamma whole-body irradiation: an in vivo microdialysis study. Can J Physiol Pharmacol 80:670-678.

El Khoury J, Toft M, Hickman SE, Means TK, Terada K, Geula C, Luster AD (2007) Ccr2 deficiency impairs microglial accumulation and accelerates progression of Alzheimer-like disease. Nat Med 13:432-438.

Frackowiak J, Potempska A, LeVine H, Haske T, Dickson D, Mazur-Kolecka B (2005) Extracellular deposits of A beta produced in cultures of Alzheimer disease brain vascular smooth muscle cells. J Neuropathol Exp Neurol 64:82-90.

François S, Bensidhoum M, Mouiseddine M, Mazurier C, Allenet B, Semont A, Frick J, Saché A, Bouchet S, Thierry D, Gourmelon P, Gorin NC, Chapel A (2006) Local irradiation not only induces homing of human mesenchymal stem cells at exposed sites but promotes their widespread engraftment to multiple organs: a study of their quantitative distribution after irradiation damage. Stem Cells 24:1020-1029.

Gate D, Rezai-Zadeh K, Jodry D, Rentsendorj A, Town T (2010) Macrophages in Alzheimer's disease: the blood-borne identity. J Neural Transm 117:961-970.

Getts DR, Terry RL, Getts MT, Müller M, Rana S, Shrestha B, Radford J, Van Rooijen N, Campbell IL, King NJ (2008) Ly6c+ "inflammatory monocytes" are microglial precursors recruited in a pathogenic manner in West Nile virus encephalitis. J Exp Med 205:2319-2337.

Grathwohl SA, Kälin RE, Bolmont T, Prokop S, Winkelmann G, Kaeser SA, Odenthal J, Radde R, Eldh T, Gandy S, Aguzzi A, Staufenbiel M, Mathews PM, Wolburg H, Heppner FL, Jucker M (2009) Formation and maintenance of Alzheimer's disease beta-amyloid plaques in the absence of microglia. Nat Neurosci 12:1361-1363.

Hawkes CA, McLaurin J (2009) Selective targeting of perivascular macrophages for clearance of beta-amyloid in cerebral amyloid angiopathy. Proc Natl Acad Sci U S A 106:1261-1266.

Hickey WF, Vass K, Lassmann H (1992) Bone marrow-derived elements in the central nervous system: an immunohistochemical and ultrastructural survey of rat chimeras. J Neuropathol Exp Neurol 51:246-256.

Ishizuka K, Kimura T, Igata-yi R, Katsuragi S, Takamatsu J, Miyakawa T (1997) Identification of monocyte chemoattractant protein-1 in senile plaques and reactive microglia of Alzheimer's disease. Psychiatry Clin Neurosci 51:135-138.

Janelsins MC, Mastrangelo MA, Oddo S, LaFerla FM, Federoff HJ, Bowers WJ (2005) Early correlation of microglial activation with enhanced tumor necrosis factor-alpha and monocyte chemoattractant protein-1 expression specifically within the entorhinal cortex of triple transgenic Alzheimer's disease mice. J Neuroinflammation 2:23.

Jantzen PT, Connor KE, DiCarlo G, Wenk GL, Wallace JL, Rojiani AM, Coppola D, Morgan D, Gordon MN (2002) Microglial activation and beta-amyloid deposit reduction caused by a nitric oxide-releasing nonsteroidal anti-inflammatory drug in amyloid precursor protein plus presenilin-1 transgenic mice. J Neurosci 22:2246-2254.

Koistinaho M, Koistinaho J (2005) Interactions between Alzheimer's disease and cerebral ischemia—focus on inflammation. Brain Res Brain Res Rev 48:240-250.

Kokovay E, Cunningham LA (2005) Bone marrow-derived microglia contribute to the neuroinflammatory response and express iNOS in the MPTP mouse model of Parkinson's disease. Neurobiol Dis 19:471-478.
Lebson L, Nash K, Kamath S, Herber D, Carty N, Lee DC, Li Q, Szekeres K, Jinwal U, Koren J, Dickey CA, Gottschall PE, Morgan D, Gordon MN (2010) Trafficking CD11b-positive blood cells deliver therapeutic genes to the brain of amyloid-depositing transgenic mice. J Neurosci 30:9651-9658.

Linard C, Marquette C, Mathieu J, Pennequin A, Clarençon D, Mathé D (2004) Acute induction of inflammatory cytokine expression after gamma-irradiation in the rat: effect of an NF-kappaB inhibitor. Int J Radiat Oncol Biol Phys 58:427-434.

Malm TM, Koistinaho M, Pärepalo M, Vatanen T, Ooka A, Karlsson S, Koistinaho J (2005) Bone-marrow-derived cells contribute to the recruitment of microglial cells in response to beta-amyloid deposition in APP/ PS1 double transgenic Alzheimer mice. Neurobiol Dis 18:134-142.

Meyer-Luehmann M, Spires-Jones TL, Prada C, Garcia-Alloza M, de Calignon A, Rozkalne A, Koenigsknecht-Talboo J, Holtzman DM, Bacskai BJ, Hyman BT (2008) Rapid appearance and local toxicity of amyloid-beta plaques in a mouse model of Alzheimer's disease. Nature 451:720-724.

Mildner A, Schmidt H, Nitsche M, Merkler D, Hanisch UK, Mack M, Heikenwalder M, Brück W, Priller J, Prinz M (2007) Microglia in the adult brain arise from Ly-6C(hi)CCR2 $(+)$ monocytes only under defined host conditions. Nat Neurosci 10:1544-1553.

Mildner A, Djukic M, Garbe D, Wellmer A, Kuziel WA, Mack M, Nau R, Prinz

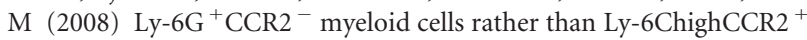
monocytes are required for the control of bacterial infection in the central nervous system. J Immunol 181:2713-2722.

Mildner A, Mack M, Schmidt H, Brück W, Djukic M, Zabel MD, Hille A, Priller J, Prinz M (2009) CCR2+Ly-6Chi monocytes are crucial for the effector phase of autoimmunity in the central nervous system. Brain 132:2487-2500.

Mucke L (2009) Neuroscience: Alzheimer's disease. Nature 461:895-897.

Naert G, Rivest S (2011) CC chemokine receptor 2 deficiency aggravates cognitive impairments and amyloid pathology in a transgenic mouse model of Alzheimer's disease. J Neurosci 31:6208-6220.

Priller J, Flügel A, Wehner T, Boentert M, Haas CA, Prinz M, Fernández-Klett F, Prass K, Bechmann I, de Boer BA, Frotscher M, Kreutzberg GW, Persons DA, Dirnagl U (2001) Targeting gene-modified hematopoietic cells to the central nervous system: use of green fluorescent protein uncovers microglial engraftment. Nat Med 7:1356-1361.

Priller J, Prinz M, Heikenwalder M, Zeller N, Schwarz P, Heppner FL, Aguzzi A (2006) Early and rapid engraftment of bone marrow-derived microglia in scrapie. J Neurosci 26:11753-11762.

Prinz M, Mildner A (2011) Microglia in the CNS: immigrants from another world. Glia 59:177-187.

Prinz M, Priller J (2010) Tickets to the brain: role of CCR2 and CX(3)CR1 in myeloid cell entry in the CNS. J Neuroimmunol 224:80-84.

Prinz M, Garbe F, Schmidt H, Mildner A, Gutcher I, Wolter K, Piesche M, Schroers R, Weiss E, Kirschning CJ, Rochford CD, Brück W, Becher B (2006) Innate immunity mediated by TLR9 modulates pathogenicity in an animal model of multiple sclerosis. J Clin Invest 116:456-464.

Raasch J, Zeller N, van Loo G, Merkler D, Mildner A, Erny D, Knobeloch KP, Bethea JR, Waisman A, Knust M, Del Turco D, Deller T, Blank T, Priller J, Brück W, Pasparakis M, Prinz M (2011) I\{kappa\}B kinase 2 determines oligodendrocyte loss by non-cell-autonomous activation of NF-\{kappa $\} \mathrm{B}$ in the central nervous system. Brain 134:1184-1198.

Ransohoff RM, Perry VH (2009) Microglial physiology: unique stimuli, specialized responses. Annu Rev Immunol 27:119-145.

Serbina NV, Pamer EG (2006) Monocyte emigration from bone marrow during bacterial infection requires signals mediated by chemokine receptor CCR2. Nat Immunol 7:311-317.

Simard AR, Soulet D, Gowing G, Julien JP, Rivest S (2006) Bone marrowderived microglia play a critical role in restricting senile plaque formation in Alzheimer's disease. Neuron 49:489-502.

Sokolova A, Hill MD, Rahimi F, Warden LA, Halliday GM, Shepherd CE (2009) Monocyte chemoattractant protein-1 plays a dominant role in the chronic inflammation observed in Alzheimer's disease. Brain Pathol 19:392-398

Stalder AK, Ermini F, Bondolfi L, Krenger W, Burbach GJ, Deller T, Coomaraswamy J, Staufenbiel M, Landmann R, Jucker M (2005) Invasion of hematopoietic cells into the brain of amyloid precursor protein transgenic mice. J Neurosci 25:11125-11132.

Tan J, Town T, Paris D, Mori T, Suo Z, Crawford F, Mattson MP, Flavell RA, Mullan M (1999) Microglial activation resulting from CD40-CD40L interaction after beta-amyloid stimulation. Science 286:2352-2355. 
Tan J, Town T, Crawford F, Mori T, DelleDonne A, Crescentini R, Obregon D, Flavell RA, Mullan MJ (2002) Role of CD40 ligand in amyloidosis in transgenic Alzheimer's mice. Nat Neurosci 5:1288-1293.

Town T, Laouar Y, Pittenger C, Mori T, Szekely CA, Tan J, Duman RS, Flavell RA (2008) Blocking TGF-beta-Smad2/3 innate immune signaling mitigates Alzheimer-like pathology. Nat Med 14:681-687.

Wisniewski HM, Wegiel J, Wang KC, Kujawa M, Lach B (1989) Ultrastructural studies of the cells forming amyloid fibers in classical plaques. Can J Neurol Sci 16:535-542.

Wisniewski HM, Barcikowska M, Kida E (1991) Phagocytosis of beta/A4 amyloid fibrils of the neuritic neocortical plaques. Acta Neuropathol $81: 588-590$
Wyss-Coray T, Lin C, Yan F, Yu GQ, Rohde M, McConlogue L, Masliah E, Mucke L (2001) TGF-betal promotes microglial amyloid-beta clearance and reduces plaque burden in transgenic mice. Nat Med 7:612-618.

Yamamoto M, Horiba M, Buescher JL, Huang D, Gendelman HE, Ransohoff RM, Ikezu T (2005) Overexpression of monocyte chemotactic protein1/CCL2 in beta-amyloid precursor protein transgenic mice show accelerated diffuse beta-amyloid deposition. Am J Pathol 166:1475-1485.

Yuan H, Gaber MW, McColgan T, Naimark MD, Kiani MF, Merchant TE (2003) Radiation-induced permeability and leukocyte adhesion in the rat blood-brain barrier: modulation with anti-ICAM-1 antibodies. Brain Res 969:59-69. 